FIVE YEAR REPORT ON THE MEDICEL FOLLOW UP OF MARSHALLESE RECEVING SPECIAL MEDICAL CARE RELATED TO 1954 BRAVO FALLOUT RADIATION (JANUARY 1992 - 1996)

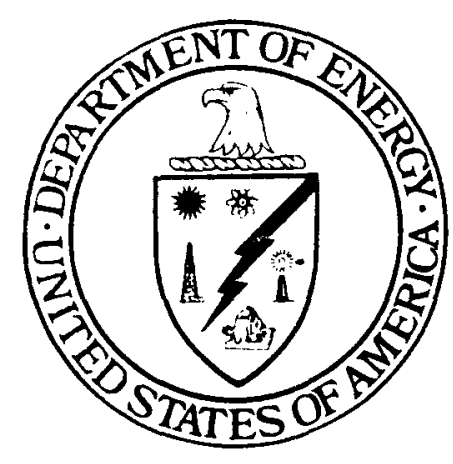

June 1999

U.S. Department of Energy Office of Environment, Safety and Health Office of International Health Studies 


\section{DISCLAIMER}

This report was prepared as an account of work sponsored by an agency of the United States Government. Neither the United States Government nor any agency thereof, nor any of their employees, make any warranty, expressed or implied; or assumes any legal liability or responsibility for the accuracy, completeness, or usefulness of any information, apparatus, product, or process disclosed; or represents that its use would not infringe privately owned rights. Reference herein to any specific commercial product, process, or service by trade name, trademark, manufacturer, or otherwise does not necessarily constitute or imply its endorsement, recommendation or favoring by the United States Government or any agency thereof. The views and opinions of authors expressed herein do not necessarily state or reflect those of the United States Government or any agency thereof.

This report has been reproduced directly from the best available copy.

Available to DOE and DOE Contractors from the Office of Scientific and Technical Information, P.O. Box 62, Oak Ridge, TN 37831; prices available from (423) 5768401 .

Available to the public from the U.S. Department of Commerce, Technology Administration, National Technical Information Service, Springfield, VA 22161 (703) $487-4650$.

Also available (with the exception of Appendix B) through the DOE Office of International Health Programs' website at http://tis.eh doe.gov/ihp. 


\title{
FIVE YEAR REPORT ON THE MEDICAL FOLLOW UP OF MARSHALLESE RECEIVING SPECIAL MEDICAL CARE RELATED TO 1954 BRAVO FALLOUT RADIATION (JANUARY 1992 - 1996)
}

\section{By}

Ashok N. Vaswani, M.D. And Jean E. Howard, M.D.

Brookhaven National Laboratory Medical Department

Upton, New York 11973

June 1999

\author{
Prepared for \\ U.S. Department of Energy \\ Assistant Secretary for Environment, Safety and Health \\ Office of Health
}




\section{FOREWORD}

As part of the United States atmospheric nuclear weapons testing program between 1946 and 1958, 23 nuclear devices were detonated at the Bikini Atoll and 43 nuclear devices were detonated at the Enewetak Atoll. A 1954 United States thermonuclear weapons test, code named "Bravo" was conducted at the Bikini Atoll and produced a nuclear yield much higher than expected. As a result, the levels and dispersion of the radioactive fallout from Bravo were significantly greater than originally expected, resulting in radioactive fallout on the inhabited atolls of Rongelap and Utrik. The Rongelap and Utrik inhabitants were evacuated from their contaminated atolls, within 48 and 72 hours, respectively, after the Bravo test. The original population directly exposed to the fallout from Bravo consisted of 241 individuals and 12 fetuses. Adsorbed dose estimates for the exposed population were on the order of 0.11 to 1.9 Gray (11 to $190 \mathrm{Rad}$ ) to the whole body and from 1.9 to 200 Gray (190 to 20,000 Rad) to the thyroid.

Public Law 99-239 mandated that the United States would “...continue to provide special medical care and logistical support thereto for the remaining 174 members of the population of Rongelap and Utrik who were exposed to radiation resulting from the 1954 United States thermonuclear Bravo test...". The Department of Energy (DOE) implemented this Congressional mandate, for the period of this report, through a contract with the Brookhaven National Laboratory.

The purpose of the Marshall Islands Medical Program is to provide medical care and treatment to the Congressionallymandated groups of Rongelap and Utrik who were exposed to fallout from the 1954 Bravo test. As of December 1998, the original Congressionally-mandated population consisted of 130 individuals.

The program offers, on a voluntary basis, an annual physical examination to these individuals, as well as annual physical examinations to volunteer comparison individuals. Medical surveillance includes a complete annual physical examination (based on American Cancer Society criteria) by a variety of specialists including gastroenterologists, hematologists, obstetricians/gynecologists, endocrinologists, oncologists, radiologists, cardiologists, nephrologists, pulmonologists, and rheumatologists.

This, the $17^{\text {th }}$ report of the Marshall Islands Program, provides information concerning the medical status of the 253 Marshallese exposed to the fallout from the 1954 Bravo test.

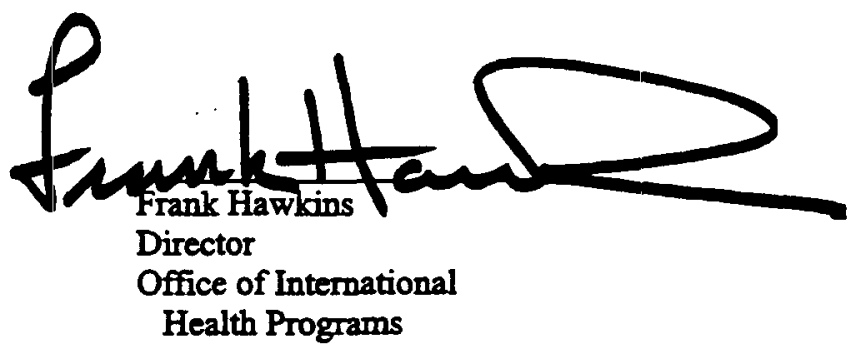




\section{DEDICATION AND APPRECIATION}

This report is dedicated to all of the patients who have participated for the past 44 years in the medical program. We wish to thank them for their voluntary participation in one of the longest running patient care programs in the history of medical practice, and sincerely appreciate their commitment. We wish them continued success in reaching their future health objectives.

The Marshall Islands Medical Program is deeply indebted to the many outstanding physicians who, despite the inevitable personal inconvenience, participated in the medical team visits of 1992-1996. It is fair to say that they were the beart of the program. 


\section{CONTENTS}

Page

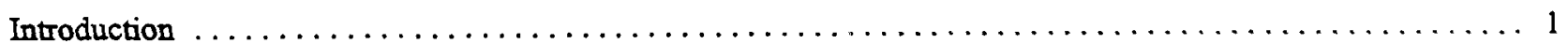

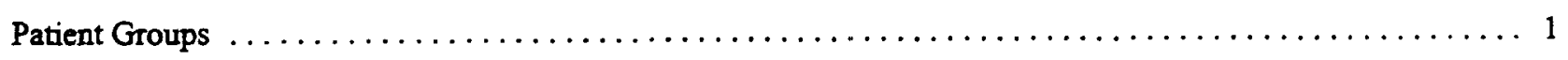

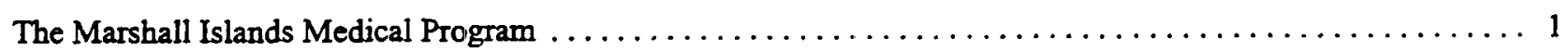

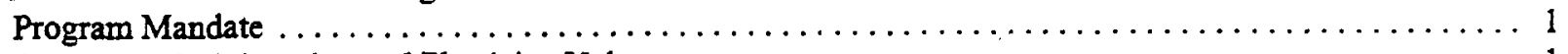

Program Administration and Physician Volunteers $\ldots \ldots \ldots \ldots \ldots \ldots \ldots \ldots \ldots \ldots \ldots \ldots \ldots \ldots \ldots \ldots \ldots \ldots$

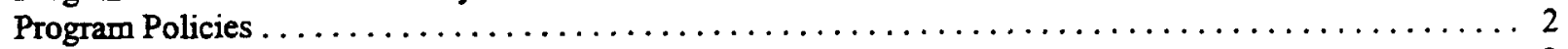

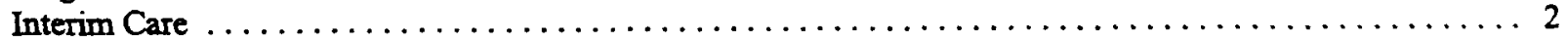

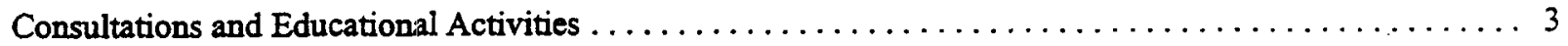

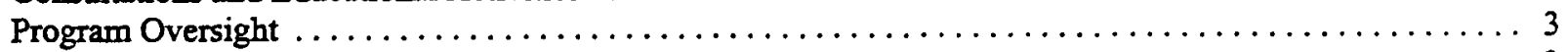

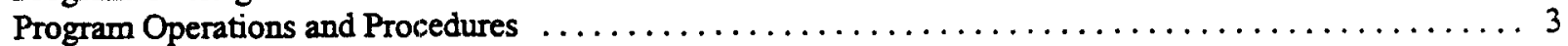

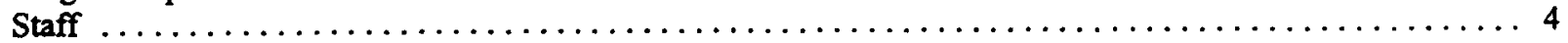

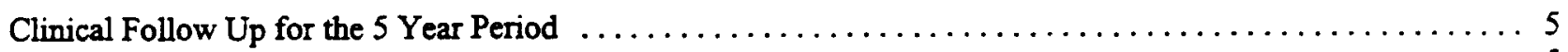

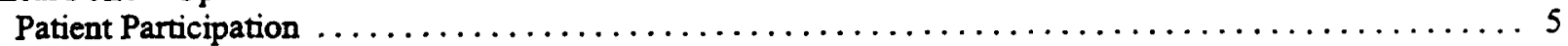

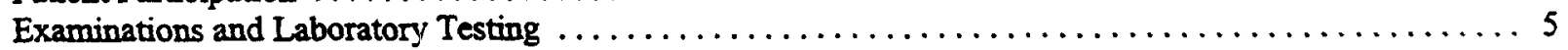

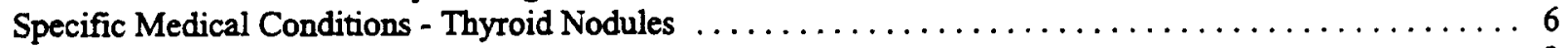

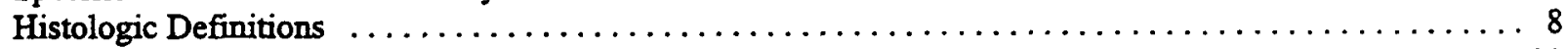

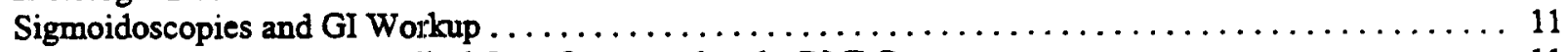

Referrals to the Tertiary Medical Care Center and to the RMI Government $\ldots \ldots \ldots \ldots \ldots \ldots \ldots \ldots 11$

Patient Deaths During 1992-1996 ...................................... 11

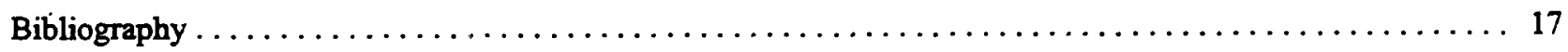

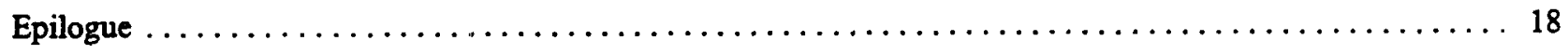

Appendix A - List of Participating Physicians and Technical Staff . . . . . . . . . . . . . .

Appendix B - Results of CBCs and Laboratory Chemistries Using Patient ID Numbers ............. B-1 
5-Year Report 


\section{INTRODUCTION}

This is the 17th and final report of the Marshall Islands Medical Program as carried out by the Brookhaven National Laboratory (BNL). The purpose of these publications has been to provide information on the medical status of 253 Marshallese exposed to radiation fallout in 1954. The medical program fulfills a commitment to disclose unique medical information relevant to public health. Details of the Bravo thermonuclear accident that caused the exposure have been published. A 1955 article in the Joumal of the American Medical Association, which described the acute medical effects on the population that required special medical care, remains a definitive and relevant description of events (Cronkite et al., 1955).

Marshallese participation in this Congressionally mandated program is voluntary. Throughout the 44 years of the program, each participating individual's relevant medical findings, laboratory data, disease morbidity, and mortality have been published in the BNL reports in a manner preserving patient confidentiality. In each report, there has been an attempt to interpret these findings and to infer the role of radiation exposure in their development. An equally important aspect of the reports has been the presentation of data that allows for analyses of the medical consequences of the Marshallese exposure.

\section{PATIENT GROUPS}

The Marshallese population mandated (the mandated group) under the Compact of Free Association Act (P.L. 99-239), originally comprised 64 persons on Rongelap Atoll who had received an estimated $190 \mathrm{rad}$ (190 cGy) of whole-body external gamma radiation, 18 on Ailinginae Atoll (Sifo Island) who received $110 \mathrm{rad}$ (110 cGy), and 159 on Utrik Atoll who received $11 \mathrm{rad}(11 \mathrm{cGy})$. For the purpose of this report, the Rongelap and Ailinginae patients are treated as one and referred to as the Rongelap group because the persons on Ailinginae were Rongelap inhabitants temporarily residing on this nearby atoll. The differences in the dose due to exposure to radioiodines were dependent on the relative distance of the atolls and islands from the Bravo test site. At the time of the accident, there were 12 pregnant women (3 on Rongelap, 1 on Ailinginae, and 8 on Utrik), each of whom received whole-body doses equivalent to doses received by the other inhabitants of their respective atolls. The twelve individuals who were exposed in utero were also considered part of the mandated group after birth. Due to the presence of radioiodines in the fallout, the thyroid gland received an exposure that was much greater than the whole-body dose; the dose due to radioiodine exposure was a function of the individual's age at the time of exposure (Lessard et al., 1985).

In 1957, a group of 86 volunteer comparison individuals from Rongelap were selected to match the mandated group by gender and age (Conard et al., 1958). A second volunteer comparison group was subsequently initiated and matched by age and gender to the mandated group. The second comparison group was statistically similar to the Rongelap and Utrik groups. Both these groups are listed in this report as the comparison group. As in previous reports, it is the expanded volunteer non-mandated group which is used for comparisons of year-to-year medical events and causes of death. The survival rates of the mandated and volunteer unmandated groups are also compared.

\section{THE MARSHALL ISLANDS MEDICAL PROGRAM}

\section{Program mandate:}

The mandate of the program, as required by the U.S. Congress in 1980 (PL 96-205, Sec. 106 (a)), specified "...a program of medical care and treatment....for any injury, illness, or condition which may be the result directly or indirectly of such nuclear weapons testing program." Subsequently, in 1985, the Compact of Free Association between the U.S. and the Republic of the Marshall Islands (RMI) allowed the Marshallese to manage their own radiation injury compensation. However, in response to a request from the RMI, a subsidiary agreement permitted the BNL medical program to continue supplemental local health care for the mandated persons. Specifically, P.L. 99-239 states: ".the President....shall continue to provide special medical care and logistical support thereto for the remaining 174 members of the population of Rongelap and Utrik who were exposed to radiation resulting from the 1954 United States thermonuclear Bravo test, pursuant to Public Laws 95-134 and 96205."

Program administration and physician volunteers:

The Marshall Islands Medical Program and its medical missions to the Marshall Islands were based at BNL since the inception of the program. The program's staff included a physician-director, an administrator, a BNL medical associate, and a Marshallese laboratory technician on Ebeye. The 
medical missions were usually conducted in the spring and fall of each year; a variety of physicians were recruited to be part of the medical team. They were skilled volunteers, primarily selected from the staff of university-affiliated or government hospitals, and often had past experience with the program. At the time of the initial medical examination, Dr. Jacob Robbins, (Chief of the Endocrinology Section, Genetics and Biochemistry Branch, National Institutes of Health, Bethesda, MD.) provided guidance and management of the program's thyroid disease aspects.

Currently, Bechtel Nevada (under DOE contract) provides logistical support to the medical program. Previously, this support had been conducted by Raytheon Services Nevada until 1995. Logistical support involves all transport, housing, and accommodation arrangements for the staff and patients traveling between Honolulu, Hawaii and the entire Marshall Islands. Additionally, Bechtel Nevada was involved in converting the program from a vessel-based to a land-based program, working closely with the U.S. Army Kwajalein Atoll personnel and executing the necessary structural changes to the medical trailers (adjacent to Kwajalein Hospital) which currently houses the medical program. The proximity to Kwajalein Hospital has eliminated the need for duplicate services that were necessary for the vessel-based program. Since 1996, all radiologic services have been performed by the Kwajalein personnel; most of the routine hematology is now completed in the Kwajalein Hospital laboratory. On request, the Marshall Islands government provides nurses, translators, and other health care workers. Bechtel Nevada offices on Majuro and $\mathrm{Kwajalein}$ oversee local staff.

\section{Program policies:}

The Marshall Islands Medical Program was created for the benefit of the mandated Marshallese patients. It was a program of radiation-related disease surveillance consisting of periodic examination and treatment of disease. Periodically, clinical investigations had been carried out by the program; the intent of these investigations was to identify present or future threats to the health of the mandated Marshallese patients, hopefully in time to prevent or limit morbidity and mortality. Based on the medical program's early findings of numerous thyroid nodules in the mandated group, thyroid hormone suppression was initiated for the Rongelap group in 1965 in an attempt to prevent thyroid nodules/carcinoma. It is possible that this prophylaxis has met with some success. As discussed in detail later in this paper, thyroid ultrasound examinations were initiated in 1994 as a means of detecting early changes in the evolution of thyroid nodules.

The Marshall Islands Medical Program provided medical care to the mandated group by visiting the islands where most subjects resided: namely, Majuro, Ebeye, Mejatto and Utrik. In addition, the medical team provided health care monitoring and surveillance for all comparison group patients.

Any individual of the special medical care group whose medical findings suggested a malignant neoplasm or other radiation-related disease was referred to secondary or tertiary medical facilities for definitive evaluation and therapy. Those persons with problems that could be effectively managed on Majuro were referred to the Marshallese Health Services. Those requiring a more extensive evaluation were referred to hospitals in Honolulu. Individuals needing referral for non-radiation related problems were sent to the Marshallese Health Service on their island of residence, where treatment was initiated.

\section{Interim care:}

During the period between the two medical missions conducted by the Marshall Islands Medical Program, the continuity of health care for the mandated and comparison groups was carried out by the Marshallese Government Health Services, which is a national health care program involving two hospitals on the most populated islands, Majuro and Ebeye. A network of clinics scattered over some 20 atolls also assisted in health care. This network of health care providers, which included physicians and public health care workers, served the entire population of the Marshall Islands, which numbers over 64,000 people. Interim care was also provided by the physicians and health workers belonging to the 177 Health Care Program. The 177 Health Care Program, operated by the Sisters of Mercy, is currently responsible for the health care of an estimated 12,600 people. Based on Majuro Atoll, the 177 Health Care Program provides primary health care to the four atoll communities of Enewetak, Rongelap, Bikini and Utrik.

At the end of each medical session, with the permission of the examinees, copies of all examination and laboratory data were delivered to the Marshall Islands Health Service hospitals on Majuro and Ebeye and to the physicians of the 177 Health Care Program. In addition, copies of physical examinations and laboratory test results completed at Kwajalein were provided to the patients themselves, thus facilitating the exchange of thorough medical information. 


\section{Consultations and educational activities:}

While providing medical surveillance to the mandated and comparison groups, the medical program physicians came into contact with family members of the mandated and other island inhabitants. It was the policy of the Depariment of Energy to support the medical program in its efforts to provide consulitatioñs and limited tueátinent to these individuals on the basis of humanitarian need and as resources permitted. Consultations were initially provided by the program staff as they visited islands during the course of the two missions. When the program became land-based at Kwajalein, consultative services were provided almost exclusively for the residents of Ebeye and the Marshallese employees working at the U.S. Army Kwajalein Atoll base on Kwajalein. The medical program also provided in-house consultations by sending specialists to the Ebeye hospital to accompany local Ebeye physicians on rounds. During each mission, lectures given by team physicians contributed to the continuing medical education of the Kwajalein and Ebeye hospital staff and physicians.

\section{Program oversight:}

The Marshall Islands Medical Program, as a satellite clinic of the Climicial Research Ceriter, Brookbaven National Laboratory, was accredited by the Joint Commission on Accreditation of Healthcare Organizations, a nationwide organization setting and monitoring performance standards for institutions dispensing medical care. By voluntarily participating in the accreditation process, the Marshall Islands Medical Program received a valuable and impartial external review of its policies and procedures, as well as an assessment of the provided services. Laboratory and radiological services, medical records, patient satisfaction, pharmaceutical services, and clinical competence of physicians were among the many items reviewed by the Joint Commission. Guidelines and questionnaires were developed to generate the information necessary for compliance with the Joint Commission's requirements.

\section{Program operations and procedures:}

Since the mandated group needed to be considered at increased rist for malignant disease (as a late complication of radiation exposure), the medical program installed a cancer-oriented annual health evaluation. The examinations followed the guidelines of the American Cancer Society and included a medical bistory, complete physical examination, annual pelvic examinations and Papanicolaou smears (PAP smears) on women, annual mammography (offered to all women forty years of age or older), annual prostate specific antigen (PSA) tests on all maies, biood count, urinalysis, stool testing for occult blood, and flexible sigmoidoscopy (every three yeârs for persoñs fifty years of age or older.) Advice on self-detection of lesions and on decreasing the risk factors for cancer was provided by printed informational materials and discussions with the public health personnel who were part of the medical team. The public health personnel also developed informational materials in the local language documenting the prevention of common communicable diseases, such as tuberculosis and acquired immune deficiency syndrome, and non-radiogenic diseases, such as diabetes and hypertension. Ophthalmologic examinations were provided by the Marshall Islands Health Services since ophthalmologists had not accompanied the medical team in the past four years. As mandated individuals were also considered at increased risk for certain endocrine problems, they received annual thyroid function blood tests and thyroid examinations by a specialist in endocrinology or thyroid surgery. Since 1994, when the thyroid ultrasound program was initiated, ultrasound-guided fine needle aspirations (FNAs) had been included as part of the surveillance, and were performed on patients with palpable nodules, or nodules greater than $10 \mathrm{~mm}$ in diameter. Anenually, thyroglobulin determinations were made on all subjects as clinical factors warranted, such as a history of thyroid cancer, or post thyroid lesion surgery. Other serologic tests were performed on a regular basis in an attempt at early detection of malignant nonthyroidal lesions. These included serum protein electrophoresis, calcium, prolactin, and alphafetoprotein levels on persons known to have positive Hepatitis B surface antigens. There was also ongoing immune competency monitoring, since the mandated persons may have been at increased risk of acquiring infectious diseases.

While the program was vessel-based, special procedures (such as thyroid uitrasound and sigmoidoscopy or colonoscopy) were performed in two hospital rooms dedicated to these purposes. Some patients were examined at dispensaries on Mejatto and Utrik, and home visits were arranged for the elderly and infirm who preferred not to be transported to the ship or flown to Kwajalein for the complete examination.

Clinical laboratory services for the missions were performed by several BNL technicians with support 
from personnel of the Kwajalein Hospital and Health Services of the RMI. Routine hematology testing was performed on a J.T. Baker 5000 electronic counter and, beginning in the fall of 1989 , on a Serono Baker $9000 \mathrm{RX}$ automatic 8-parameter cell counter. Leukocyte differentials and platelet counts were part of each evaluation. Clinical chemistry tests were performed on Eastman Kodak EktaChem DT60, DTSC or DTE analyzers. These analyzers provided a wide variety of basic chemistry tests with a small amount of disposable waste. Uninalysis included a dipstick examination and, when indicated, microscopic analysis. Stool exams were performed at physicians' request for identification of parasites and occult blood.

Roentgenographic services on board the vessel, Offshore Venture, were provided using a dedicated mammography unit (beginning in 1995, mammography was performed at the U.S. Army Hospital on Kwajalein Island) and a standard X-ray unit manufactured by the Bennett Corporation, Long Island, NY. X-ray interpretation was done at the time of examination. However, if no radiologist was part of the medical team, the $x$-ray films were returned to $B N L$ and then referred to a consultant radiologist, Dr. Haroid Âtikins at the State Üniversity of New York, Stony Brook. Once the program was land-based, radiographic tests and mammograms were performed using the GE units located at Kwajalein Hospital. A volunteer radiologist physician always accompanied the medical team, eliminating the need for $x$-rays to be sent to the U.S. for review.

A portable battery powered electrocardiograph machine was available. Electrocardiogram interpretation was done at the time of examination, with a copy often given to the patient. All electrocardiograms were subsequently returned to BNL and then referred to a consultant cardiologist (Dr. M. Zema) at Brookhaven Memorial Hospital on Long Island, NY, for definitive analysis.

A General Electric thyroid ultrasound machine was purchased for the detection of thyroid noduies and used for ultrasound-guided fine needle aspiration of thyroid noduies suspected of malignancy. A second ultrasound machine (a Hewlett-Packard Sonos 100) was a vailable for assessuent of such diverse items or factors as abdominal pain, hematuria, gestational age, and cardiac disease. It was used only under the guidance of a radiologist or subspecialist physician with expertise in ultrasound examination.

Sera collected during the routine physical examinations were analyzed at the time of patient examination, as clinically indicated. The remainder were frozen for further testing upon return to BNL. The latter tests were performed at commercial laboratories. One of these referral laboratories, Labcorp, of Garden City, New York carried out all routine and special chemistries involving thyroid hormone analysis. Labcorp also was responsible for the PAP smears. All other cytology and pathology was sent to the Pathology Department, State University of New York at Stony Brook, for analysis of thyroid biopsy specimens and special cytology for GI or GYN biopsy specimens.

The samples analyzed by the BNL staff were subject to a laboratory environment with quality control and quality assurance and involved routine calibration, maintenance, and monitoring of all instrumentation. Daily tri-level analysis of reference materials was performed on the hematology analyzer. The chemistry analyzer was calibrated prior to each mission, and bilevel quality control samples were run on all analyses. Pursuant to the enactment of the Clinical Laboratory Improvement Analysis Legislation, the program subscribed to Wisconsin State Hygiene Laboratory proficiency testing. When necessary, laboratory instrumentation was inspected and repaired by company service representatives. Other instrumentation, such as sphygmomanometers, electrocardiograph machines, and doppler units, was periodically calỉbrated and had routine preventative maintenance performed between missions at BNL.

Additional quality assurance methods included the use of patient questionnaires. These questionnaires translated into Marshallese - solicited criticism and advice for improving the medical program's operation. One important quality assurance mechanism was the mission's use of volunteer physicians from across the United States. The on-site advice, commentary, and criticism of these physicians helped to maintain the high standards of patient care. Additionally, all physicians participated in on-site peer review. Finally, the results of these and other mechanisms of quality assurance were reviewed by the BNL Clinical Research Center Quality Assurance and Care Committee. Also included in that review was the appropriateness of using anti-infective agents; a certified medical records consultant randomly reviewed approximately 20 percent of the records for accuracy and completeness.

\section{Staff:}

The volunteer medical staff was drawn from excellent medical centers and private practices throughout the United States. During the past few years, each mission was successfully mamned by a core of physicians comprising the medical director (internal 
medicine), an endocrinologist, another internist or family practitioner, a gynecologist and a radiologist. These physicians provided the program with a wide range of up-to-date clinical experience and perspective that contributed to better patient care. Appendix A lists the physicians by their respective specialties, as well as medical team personnel involved in the 1992-1996 missions.

\section{CLINICAL FOLLOW-UP FOR THE 5 YEAR PERIOD}

\section{Patient participation:}

As previously indicated, patient participation in the Marshall Islands Medical Program was entirely voluntary. Prior to the arrival of the medical team in the Marshall Islands, local newspapers and radio stations announced the imminent arrival of the medical groups and the location of the proposed examination sites. These announcements permitted the patients to make appropriate arrangements for their visits. For the first four years of this reporting period - when the program was vessel-based - the boat docked in Majuro port, where patients were scheduled for their medical evaluations. At the end of approximately one week, the Offshore Venture departed for Kwajalein. The vessel, with on-board medical facilities, docked at Ebeye, where the medical staff evaluated the mandated and comparison groups residing on Ebeye. The boat also made a two-week trip to the outer islands of Utrik and Mejatto. The total duration of the mission was approximately 4-5 weeks.

\section{2-1996 Marshall Islands Medical Program}

At the beginning of the 1992 reporting period, there were an estimated 154 patients in the mandated groups and 113 patients in the volunteer groups. These patients were given the opportunity to return on an annual basis; the actual percentage of mandated and comparison patients who availed themselves of these services is listed in Table 1. Patient acceptance of the transference of care from vessel-based to landbased was enthusiastic, as patients were afforded more flexibility in scheduling appointments. During vessel-based examinations, a patient who had to be seen in Majuro only had a total of seven days to schectule a visit. Since the land-based program lasted approximately four weeks, patients had more time to schedule visits and were more likely to complete a physical examination for that year. Overall, the acceptance of the land-based program by all of the patients was extremely positive. They were able to receive reports of their most recent blood tests done on Kwajalein. At the end of each mission, copies of these reports were also sent to the respective primary care physicians on Ebeye, Majuro or the outer islands.

Patients who reside outside of the Marshall Islands are not necessarily represented in the patient group examined during the five-year period. These patients are predominantly located on the islands of Hawaii; some have migrated to mainland USA. All patients were notified about pending missions; however, they may or may not have availed themselves of these services. Appropriate arrangements had been made for these non-resident patients residing in Hawaii to receive care at a tertiary center in Honolulu or elsewhere.

\section{Post-1996 Marshall Islands Medical Program.}

As previously noted, since 1996 the program has been land-based and located at Kwajalein Hospital. Two trailers, refurbished for the purpose of the medical program, included a male examining room, a female examining room, a gynecological examining room, an endocrinology area, laboratory and pharmacy facilities, a waiting area for the patients, and a room for administrative purposes. Two special procedure rooms were leased from the hospital - one for performing sigmoidoscopy/colonoscopy procedures and one for a thyroid ultrasound unit.

In addition, the hospital laboratory and radiological services were made available for $\mathrm{CBC}$, chemistries and urinalysis and other routine tests. The hospital technician who performed mammograms and $x$-rays was also available to schedule these tests. Thyroid ultrasound was done by a specially trained technician who had been subcontracted for each of the medical missions for the past five years.

\section{Examinations and laboratory testing:}

Generally, in keeping with the preservation of cultural sensitivities and individual wishes, male patients were examined by a male physician and female patients by a female physician. Blood was drawn for routine and special chemistries, and other tests deemed necessary were conducted at the hospital. The landbased program allowed for greater ease in obtaining tests and prevented duplication of the laboratory equipment or personnel.

It should be noted that, once the mission was landbased at Kwajalein, the routine and screening mammogram procedures increased dramatically, due to the availability of an approved mammography site. 
TABLE 1. Total number of patients seen each year between 1992 and 1996.

\begin{tabular}{|c|c|c|c|c|c|c|}
\hline GROUP & Number & 1992 & 1993 & 1994 & 1995 & 1996 \\
\hline Mandated $^{*}$ & 154 & $92 \%$ & $84 \%$ & $83 \%$ & $83 \%$ & $84 \%$ \\
\hline Comparison & 113 & $79 \%$ & $65 \%$ & $61 \%$ & $55 \%$ & $79 \%$ \\
\hline
\end{tabular}

*This includes patients from Rongelap and Utrik combined at the beginning of fiscal year 1992.

Additionally, a radiologist began accompanying each mission, so that an immediate mammogram reading was available, greatly facilitating female patient care, as mammograms were accepted by virtually all of the women. Additionally, a gastroenterologist accompanied the missions on a regular basis for the primary purpose of performing routine flexible sigmoidoscopies; this physician was available for consultations, and after 1995, performed colonoscopies and upper endoscopies at U.S. Army Hospital on Kwajalein Island, thereby decreasing the need to refer patients off-isiand to Honoiulu.

The total number of special procedures and mammographic tests completed for the entire duration of the Five-Year Report are listed in Table 2.

\section{Specific medical conditions - thyroid nodules:}

During the transition between vessel-based and land-based operations, one of the major emphases for the Marshall Islands Medical Program was to institute the detection of thyroid nodules by use of the ultrasound technique. The initial ultrasound equipment was supplemented by a 7.5 megahert ultrasound machine from General Electric, which was used predominantly for the detection of thyroid nodules. At the end of the previous five-year report (which ended in 1991), there were several questions left unanswered regarding the thyroid nodules:

-- will the entire mandated and volunteer comparaison groups remained susceptible to new nodule formation?

- what is the role of gender in the development of thyroid nodules?

- what are the roles of radiation dosage and age in relation to the detection of nodules?

- was the nodule formation induced as a function of exposure to previous radiation?

- did the radiation increase the incidence of occult carcinomas?

Most of these questions were addressed in the previously-cited Cronkite paper. A summary of some of the important tables from that paper follows.
During the spring and fall 1994 surveys, thyroid ultrasounds were done on a total of 164 patients: 117 from the mandated group, and 47 from the volunteer comparison groups (Table 3). The total incidence of thyroid nodules detected in all of these groups was $25.0 \%$. A total of 117 of these subjects (non-surgical patients) had not undergone any surgical procedures. Of these, $28.2 \%$ had developed thyroid nodules detectable by ultrasound.

The percentage of patients who had nodules greater than $10 \mathrm{~mm}$. in diameter (the criteria for either an FNA or surgical exploration) was $10.4 \%$ for the total population of 164 patients, and $12.8 \%$ when the 117 non-surgical patients were taken into consideration. The number of patients who had nodules greater than $10 \mathrm{~mm}$ in diameter detected by ultrasound during the 1994 survey is depicted in Table 4.

All of these findings have been published in a recent publication, Thyroid Disease Among the Rongelap and Utrik Population - An Update (Howard, etal., 1997). The initial thyroid ultrasound done in 1994 served as the basis for the majority of patients who came for annual visits.

In 1995 and 1996, an additional 230 ultrasounds were done on all patients from Rongelap, Utrik, and the comparison group. These are reported in Tables 5 and 6.

During the 1995 and 1996 medical missions, a total of 240 ultrasounds were done on 113 patients. Of the 50 patients from the mandated group from Rongelap tested in 1995 and 1996,22 subjects (or $\mathbf{4 4}$ percent) had detectable thyroid nodules on ultrasound. Of the 105 patients from the mandated group from Utrik testing in 1995 and 1996, 50 subjects (or 47 percent) had detectable thyroid nodules on ultrasound).

These numbers were similar between the two groups. In addition, 41 subjects (or 44 percent) of the comparison group also had nodules. Therefore, there does not appear to be any difference in detectable nochules between the mandated group and the volunteer comparison group. Of the subjects seen between 1995 and 1996, a total of 62 percent of the women were on thyroid suppression therapy. A total of 51 percent of 
TABLE 2. Number of procedures done each year between 1992-1996.

\begin{tabular}{|l|c|c|c|c|c|}
\hline \multicolumn{1}{|c|}{ Procedure } & 1992 & 1993 & 1994 & 1995 & 1996 \\
\hline X-rays & 40 & 47 & 173 & 118 & 90 \\
\hline Mammograms & 20 & 24 & 39 & 47 & 64 \\
\hline GI procedures & $\ldots$ & 23 & 30 & 44 & 35 \\
\hline
\end{tabular}

TABLE 3. Percentage of subjects in each patient group with thyroid nodules during the 1994 survey.

\begin{tabular}{|l|c|c|c|c|c|c|}
\hline & $\ddots$ & \multicolumn{3}{c|}{ All } & \multicolumn{3}{c|}{ Non Surgical } \\
Patients \\
\hline & $\begin{array}{c}\text { Total } \\
\text { Patients }\end{array}$ & $\begin{array}{c}\text { Patients with } \\
\text { nodules* }\end{array}$ & Percent & $\begin{array}{c}\text { Total } \\
\text { Patients }\end{array}$ & $\begin{array}{c}\text { Patients with } \\
\text { nodules* }\end{array}$ & Percent \\
\hline Rongelap & 47 & 6 & 28.7 & 23 & 5 & 19.7 \\
\hline Utrik & 70 & 23 & 42.7 & 55 & 17 & 47.0 \\
\hline Comparison & 47 & 12 & 28.6 & 39 & 11 & 33.3 \\
\hline Total & 164 & 42 & 25.0 & 117 & 33 & 28.2 \\
\hline
\end{tabular}

*Nodules detected only by ultrasound.

TABLE 4. Number of patients who had nodules greater than $10 \mathrm{~mm}$ in diameter, detected by ultrasound, during the 1994 survey.

\begin{tabular}{|l|c|c|}
\hline & AlPatients & Non Surgical Patients \\
& Number \\
\hline Rongelap & 3 & 2 \\
\hline Utrik & 9 & 8 \\
\hline Comparison & 5 & 5 \\
\hline
\end{tabular}


TABLE 5. Total number of subjects with thyroid nodules detected on ultrasound in 1995 - 1996.

\begin{tabular}{|l|c|c|c|}
\hline \multicolumn{1}{|c|}{ Gender } & $\begin{array}{c}\text { Mandated } \\
\text { Group }\end{array}$ & $\begin{array}{c}\text { Mandated } \\
\text { Group }\end{array}$ & Comparison \\
\hline & Rongelap & Utrik & Rongelap \\
\hline Females & 13 & 26 & 20 \\
\hline Males & 9 & 24 & 21 \\
\hline TOTAL & 22 & 50 & 41 \\
\hline
\end{tabular}

TABLE 6. Total Number of ultrasounds performed on 113 patients which showed detectable nodules.

1995

\begin{tabular}{|l|c|c|c|c|}
\hline & Females & Males & Females & Males \\
\hline Number & 44 & 54 & 85 & 57 \\
\hline$<10 \mathrm{~mm}$ & 34 & 39 & 60 & 43 \\
\hline$>10 \mathrm{~mm}$ & 19 & 23 & 28 & 21 \\
\hline$<10 \&>10 \mathrm{~mm}$ & 9 & 8 & 13 & 7 \\
\hline Mean \# of nodules & 1.68 & 1.44 & 1.59 & 1.47 \\
\hline
\end{tabular}

the men were on thyroid suppression therapy. The thyroid stimulating hormone (TSH) levels in all of these patients between 1995 and 1996 were within normal limits. The availability of the ultrasound equipment also permitted FNA of the thyroid at the medical hospital base in Kwajalein. Table 7 lists all patients with nondiagnostic or suspicious FNAs that were referred for surveys. Initial success with thyroid FNAs was minimal while the program was still vessel-based on the Offshore Venture. Since the program was installed in the trailers on the Kwajalein Hospital site, greater usage of the thyroid uitrasound technique for biopsies occurred. As a result, fewer referrais were sent to Honoluiu.

\section{Histologic definitions:}

Once the FNAs were completed, the specimens were sent back to New York for histologic diagnosis. If surgery was necessary, patients were referred to the contract tertiary care center, Straub Clinic and Hospital, in Honolulu. Histological classification occurred according to the pathology group at the Straub Clinic and Hospital.
The patients listed in Table 8 had surgery between 1992 and 1996. All of the surgical procedures were performed at the Straub Clinic and Hospital.

The thyroid ultrasound and pathology findings are summarized below:

The non-neoplastic adenomatous nodules were associated with higher doses of radiation, while neoplastic nodules developed in individuals who received lower doses of radiation. Women generally tended to have a larger number of palpable thyroid nodules than men. There were no significant differences between the thyroid noduies detected by ultrasound in the Rongelap and Utrik mandated communities, as compared to the volunieer group. Eight of the mandated patients were referred for surgical excision of the thyroid nodules, which were only detectable by ultrasound (proving the thyroid ultrasound to be a solid means of detecting small nonpalpable nodules). Of these patients, one had a hemorrhagic cyst, three had adenomatous goiters, two had follicular adenomas, one had adenomatous hyperplasia, and one had adenomatous hyperplasia with occult papillary carcinoma. The thyroglobulin levels in the patient who had occult papillary carcinaoma were 
TABLE 7. FNAs Performed 1992-1996 (* next to subject indicates patient is also included in Surgery table which is Table 8). All nondiagnostic or suspicious FNAs were referred for surgery.

\begin{tabular}{|c|c|c|}
\hline Subject & Date of FNA & Islend Group \\
\hline No. 1 & 1996 & Mandated \\
\hline No. 2 & 1995 & Mandated \\
\hline No. $3^{*}$ & 1995 & Mandated \\
\hline No. 4 & 1996 & Mandated \\
\hline No. 5 & 1995 & Mandated \\
\hline No. 6 & 1994 & Mandated \\
\hline No. $7^{*}$ & 1994 & Mandated \\
\hline No. 8 & 1996 (twice) & Mandated \\
\hline No. 9 & 1996 & Comparison \\
\hline No. 10 & $1995 \& 1996$ & Comparison \\
\hline No. 11 & 1996 & Comparison \\
\hline No. 12 & 1996 & Comparison \\
\hline No. 13 & 1994 & Comparison \\
\hline No. 14 & $1994 \& 1995$ & Comparison \\
\hline No. 15 & 1994 & Comparison \\
\hline No. 16 & 1994 & Comparison \\
\hline No. 17 & 1995 & Comparison \\
\hline No. 18 & 1995 \& twice in 1996 & Comparison \\
\hline No. $19^{*}$ & $1994,1995, \& 1996$ & Mandated \\
\hline No. 20 & 1996 & Mandated \\
\hline No. 21 & 1996 (twice) & Mandated \\
\hline No. 22 & 1996 & Mandated \\
\hline No. 23 & 1996 (twice) & Mandated \\
\hline No. $24^{*}$ & 1994 (twice) & Mandated \\
\hline No. 25 & 1994 & Mandated \\
\hline No. 26 & $1994 \& 1996$ & Mandated \\
\hline No. $27^{*}$ & 1994 & Mandated \\
\hline
\end{tabular}


TABLE 7 (continued). FNAs Performed 1992-1996 (* next to subject indicates patient is also included in Surgery table which is Table 8). All nondiagnostic or suspicious FNAs were referred for surgery.

\begin{tabular}{|c|c|c|}
\hline Subject & Date of FNA & Island Group \\
\hline No. $28^{*}$ & 1994 & Mandated \\
\hline No. $29^{*}$ & By Japanese & Mandated \\
\hline No. 30 & 1994 & Mandated \\
\hline No. 31 & $1995 \& 1996$ & Mandated \\
\hline No. 32 & $1994 \& 1995$ & Mandated \\
\hline No. 33 & 1995 & Comparison \\
\hline No. 34 & 1994 & Comparison \\
\hline
\end{tabular}

TABLE 8. Thyroid Surgery Patients 1992-1996.

\begin{tabular}{|c|c|c|c|}
\hline Subject & $\begin{array}{c}\text { Date of } \\
\text { Surgery }\end{array}$ & Histopathologic Diagnosis & Island Group \\
\hline No. 1 & 1994 & Follicular Adenoma & Mandated \\
\hline No. 2 & 1996 & Adenomatous Hyperplasia & Mandated \\
\hline No. 3 & 1994 & Atypical Follicular Cells, No Thyroid Tissue & Mandated \\
\hline No. 4 & 1996 & Adenomatous Goiter & Mandated \\
\hline No. 5 & 1994 & Adenomatous Goiter & Mandated \\
\hline No. 6 & 1994 & Adenomatous Goiter & Mandated \\
\hline No. 7 & 1995 & Adenomatous Hyperplasia and Occult Papillary & Marcinoma \\
\hline No. 8 & 1995 & Follicular Adenoma, Focal Benign Hyalinized Nodule, \\
Focal Benign Adenomatous Hyperplasia & Mandated \\
\hline
\end{tabular}

within normal limits. An interesting finding was that thyroid suppression had been initiated in the Rongelap group earlier in the course of the Marshall Islands Medical Program. Interestingly, the patients in the Rongelap mandated group had a lower incidence of ultrasound detectable thyroid nodules, as compared to the Utrik group. Also of interest was the fact that of the five patients who had thyroid tissue at surgery, four were from Utrik and only one from Rongelap. It is noteworthy that thyroid suppression does appear to have either reduced the incidence of thyroid cancers due to continued suppression of the
TSH, or reduced the incidence of new thyroid cancers in the remnant thyroid tissue. The higher percentage of nodules detected between 1995 and 1996 is a reflection of the increased number of patients that were followed up during these two years. An incidence of approximately $28 \%$ in the group that had been studied up to 1994 was previously reported.

In either event, patients from Utrik did not have or need many surgical procedures, and had not been previously suppressed with thyroid bormone replacement. Therefore, the findings of a higher incidence of thyroid surgery in this group may simply 
be a reflection of the slow, but benign, process of nodule formation, which appears to be inevitable in virtually all endocrine tissues.

Several studies have shown that the addition of $\mathrm{L}$ thyroxine to patients who are being treated for benign solitary cold nodules is effective in suppressing the growth of the nodules (LaRosa et al., 1995). It should be noted that none of the thyroid nodules that were detected by ultrasound in the group were palpable. Numerous studies have shown that clinical palpation of the thyroid is less sensitive than thyroid ultrasonography when identifying nodules. The detection limit for most thyroid examinations is a minimum of $1.5 \mathrm{~cm}$ in diameter (Tan et al., 1995).

Several long-term studies have been conducted in patients who have previously undergone thyroid surgery and radioactive iodine ablation for papillary thyroid carcinoma. In a long-term study of over 35 years, cumulative recurrence rates of thyroid cancers were less than 9\% (Mazzaferri and Jhiang, 1994).

The second major emphasis for this report was to follow up on mammograms in women, both in the mandated and volunteer comparison groups. No mammography was performed in 1994 because it was agreed that the vessel-based unit was not up to current standards. In 1995, arrangements were made with the U.S. Army Hospital on Kwajalein Island to refer all female patients for routine mammography. In 1995 , patients requiring diagnostic mammography were referred to the Straub Clinic and Hospital. In 1996, with the inception of the land-based program and the availability of a radiologist, diagnostic mammography was performed at the U.S. Army Hospital on Kwajalein Island. During the course of the five years, palpable nodules were detected on a number of patients. Initially, the majority of these patients were referred off-site to Honolulu for diagnostic biopsies and surgical procedures. These patients were subsequently followed-up through the Straub Clinic and Hospital. In 1996, arrangements were made with the Kwajalein surgical staff to perform routine biopsy procedures, thus creating a reduction in the number of Honolutu referrals. There were a total of 39 referrals made for mammogramrelated abnormalities. These patients were referred for surgical procedures or evaluations at $\mathrm{K}$ wajalein or Honoluhn. A number of these procedures turned out to be benign, and only one patient was detected to have breast cancer. This patient was treated with radiation therapy in Honolulu, since that was her location of residence.

The third major initiative for this report was to institute the blood tests for PSA for all males who had palpable prostate enlargements. This resulted in approximately eight patients with detectable levels of PSA, who required referrals to the urology services in Honolulu.

\section{Sigmoidoscopies and GI workup:}

Sigmoidoscopies were done on the Offshore Venture and at the U.S. Army Hospital on Kwajalein Island. Once the program became land-based, two additional Olympus flexible sigmoidoscopy units were purchased for the medical program. This increased the efficiency of the gastroenterologist's time. Also, it should be noted that both units were in compliance with the increasingly stringent sterilization requirements. The sigmoidoscopies, colonoscopies and proctoscopic examinations were conducted either by the visiting gastroenterologist, or by one of the surgeons located permanently on Kwajalein.

Hepatitis B surface antigen was detectable in a number of patients, who were routinely monitored with alphafetoprotein for the development of any hepatocellular problems. This was an ongoing procedure, and patients were treated annually with alphafetoprotein levels, hepatic ultrasound, and liver biopsies, as indicated.

Hematological evaluations were continued when appropriate by means of routine blood counts, platelet counts, serum protein electrophoresis, and bone marrow aspirations. The results of the CBC's and chemistries are listed in Appendix B.

\section{Referrals to the Tertiary Medical Care Center and to the RMI Government:}

As previously indicated, the number of referrals to the Tertiary Medical Care Center in Honolulu decreased after the program became land-based. The overall referrals for various patients are listed in Table 9. In general, the thyroid-related referrals were mainly to repeat thyroid FNAs, to perform surgical excision of thyroid nodules, and to follow up with radioactive iodine scans for those patients who had previous thyroid cancers.

\section{Patient Deaths During 1992 - 1996:}

There were a total of 25 of the original 253 mandated patients and 14 of the 227 volunteer comparison patients who expired during this reporting period. The total percentage of mandated patients who expired during this reporting period was $9.99 \%$; the expiration percentage of the volunteer comparison patients who returned for annual visits was $6.2 \%$. After 42 years, there still continue to be few differences 
TABLE 9. Rieferrals to the Tertiary Care Center and to the RMI Government.

\begin{tabular}{|c|c|c|}
\hline Disenses/Conditions & No. of Subjects & $\%$ of Total \\
\hline Anemia & 26 & 7 \\
\hline Back pain & 1 & $<1$ \\
\hline Breast & 39 & 11 \\
\hline Cardiology & 3 & 1 \\
\hline Dental & 2 & 1 \\
\hline Diabetes & 13 & 4 \\
\hline Endocrine visits & 10 & 3 \\
\hline Gastroenterology & 73 & 21 \\
\hline Gynecology & 30 & 9 \\
\hline Hypertension & 10 & 3 \\
\hline Leg cramps & 1 & $<1$ \\
\hline Non-thyroid neck mass & 3 & 1 \\
\hline Neurological & 2 & 1 \\
\hline Ophthalmological & 12 & 3 \\
\hline Osteoarthritis & 2 & 1 \\
\hline Pituitary tumor & 1 & $<1$ \\
\hline Pulmonary & 18 & 5 \\
\hline Skin lesions & 1 & $<1$ \\
\hline Surgery (non-thyroid) & 5 & 1 \\
\hline Thyroid & 70 & 20 \\
\hline Urology & 26 & 7 \\
\hline Total referrals & 348 & $100 \%$ \\
\hline
\end{tabular}

between the percentage of patients in the mandated groups compared to the gender and age-matched volunteer patients. It should be noted that because many patients lived on atolls or outer islands located a great distance from major population centers, the cause of death is usually not recorded and, therefore, unknown. Individual summaries for each of the patients who expired within each group (mandated and volunteer comparison) are shown below:
Deceased patients in the mandated groups are specified by island: Rongelap (R) and Utrik (U).

Subject No. 1 (R). This was an 82-year old woman whose main symptoms were inability to walk, B12 deficiency, and probably mild myelodysplastic syndrome. She also had persistent psoriasis and hypothyroidism. She was being treated with Synthroid $200 \mathrm{mcg}$ daily and B12 injections for the anemia. The cause of death is unkmown. 
Subject No. 2 (R). This patient was a 60-year old male who had status post thyroidectomy and laryngectomy for squamous cell carcinoma. His laryngeal carcinoma developed in 1992, when he first had symptoms of progressive hoarseness for approximately 8 months. The cliagnosis was made by laryngoscopy and the findings were of multiple nodules among the vocal chords. He also received chemotherapy for metastatic laryngeal carcinoma to the right upper lobe of the lung. His thyroidectomy was in 1977 for a benign disease. He had a history of hypothyroidism for which he was being treated with Synthroid $200 \mathrm{mcg}$ daily. The cause of death was not reported, but may have been due to metastatic laryngeal carcinoma to the right upper lobe of the lung.

Subject No. 3 (R). This was an 82-year old male who was last seen in 1992 complaining of mild back pain which was due to an injury. His physical examination was unremarkable at that time, and his only problems were the presence of bilateral cataracts and stable anemia. He also had very mild renal insufficieney as evidence of a slight increase in serum creatinine. The patient was also known to have hereditary neuropathy. The cause of his death is unknown.

Subject No. 4 (R). This was a 60-year old male who was seen in March 1996. He had a history of blood in his stools for which he was being examined by colonoscopy. This test found no evidence of malignancy, and no identifiable lesions were visible. The patient had mild renal insufficiency as evidence of slight increase in serum creatinine and B12 deficiency. He was also noted to have an abnormal PSA. He was also being treated with Vasotec for mild hypertension. The immediate cause of his death is unknown.

Subject No. 5 (R). This was a 64-year old male who was last seen in March 1994, and his history included hypothyroidism for which he received Synthroid $200 \mathrm{mcg}$ daily. His past medical history inchuded a mild degree of remal impairment, and minimal upper GI reflux treated intermittently with Maalox. He was also known to have Hansen's disease with extensive multiple amputations of his fingers and toes. He also had below knee amputation of the right leg also due to Hansen's disease. The cause of his death is unknown.

Subject Na. 6 (U). This was a 78-year old female who was last seen in 1995 as a home visit. She had a long standing history of diabetes mellitus and was treated with Micronase $5 \mathrm{mg}$ daily. She was also receiving $100 \mathrm{mcg}$ of Synthroid daily for a prior history of thyroidectomy for benign disease. When she was last seen at home, she was confined to bed and had a low blood pressure, but the rest of the physical exam was unremarkable. The immediate cause of death is unknown.

Subject No. 7 (R). This was a 78-year old male who was last seen in 1992 and expired in 1995. He declined visits to the medical facilities when he was contacted during the missions. When he was last seen, he had a history of decreasing vision and difficulty walking. He had a fixed flexion deformity of his knee and diminished flexion of the spine. He also had hypothyroidism for which he was receiving $200 \mathrm{mcg}$ of Synthroid daily. In 1991, he had been seen at Straub Clinic and Hospital for tuberculosis. He also had a history of cerebral vascular accident with left-sided hemiparesis. The cause of his death is unknown.

Subject No. 8 (U). This was an 80-year old male who was last seen in 1991. The patient had a history of left-sided hemiparesis and infection of his right foot. He had a previous history of left lower extremity below leee amputation. He also had a history of peripheral neuropathy and mild cataracts. The immediate cause of his death was not reported.

Subject No. 9 (U). This was a 92-year old male who expired in Majuro in 1993, due to pneumonia and senility. He was last seen by the medical program in 1992 in a home visit. At that time, his predominant complaints were mild dermatitis, constipation and a pilonidal cyst. He was also found to bave benign prostatic hypertrophy. He was given symptomatic treatment at that time with local creams for his skin lesions and Dulcolax for his constipation. He was adritud to Majuro Hospinal for a wral of five days and expired in the hospital.

Subject No. 10 (U). This was an 89-year old male who had a history of iron deficiency amermia and guaiac positive stool. He was last seen as a referral to Straub Clinic and Hospital for a workup of a large scrotal mass, and low hemoglobin and hematocrit. The patient had surgery for left inguinal hernial repair and leftsided orchiectomy. The pathology report of this specimen indicated that the patient had a Leydig cell tumor with evidence of putmonary metastases as seen on chest $x$-ray. The cause of his death was not reported, but may have been due to the metastatic Leydig cell tumor. 
Subject No. 11 (U). This was a 45-year old female who was seen by the medical program in March 1993. She had a history of long standing and poorly controlled diabetes mellitus. In May 1990, she had a left breast mass which was found to be benign. This patient was admitted to Majuro Hospital in August 1993, and the immediate cause of her death was reported to be cardiac arrest which was presumed to be due to electrolyte imbalance secondary to chronic diarrhea.

Subject No. 12 (U). This was an 82-year old male who was last seen as a home visit in 1995. The patient expired in March 1996. He had a history of diabetes mellinus with acceptable control, and chronic anemia which was stable. He also had status post right toe amputations due to his diabetes. His diabetes was adequately controlled with Micronase $10 \mathrm{mg}$ daily. His prior history included surgery for benign prostatic hypertrophy in 1980, and surgery for cataracts in 1987 and 1990 . The immediate cause of his death is unknown.

Subject No. 13 (U). This was a 40-year old male who was last seen in 1992. The patient had a history of hypertension for which he was being treated with Vasotec $10 \mathrm{mg}$ daily. The patient also had an elevated prolactin level which was not related to hypothyroidism or the result of other medications that he was receiving. Work up of his pituitary gland included a CT scan which showed an empty sella associated with elevated levels of prolactin. The high levels of prolactin also caused bim to be impotent. The patient also had probable coronary artery disease with cardiomyopathy, and there was evidence of myocardial infarction on an old cardiogram. The patient as a chronic smoker and also had been a heavy alcohol drinker, which may have contributed to the cardiomyopathy. The inmediate cause of his death is unknown.

Subject No. 14 (U). This was a 71-year old woman who was last seen at the medical mission in March 1993. She was referred to Straub Clinic and Hospital in May 1991 for a questionable abdominal mass. Work up at that time was umremarkable for any masses. She was seen again in 1992. There was a concern of weight loss. She was seen once more in April 1993 for recurrent abdominal problems. A mass was discovered by CT in the region of the aorta and a biopsy of this mass indicated poorly differentiated adenocarcinoma, with an unknown primary source. The cause of death is unknown, but may have been due to the poorty differentiated adenocarcinoma.
Subject No. 15 (U). This was a 90-year old woman who was last seen in the medical program in April 1992. She had a history of constipation, hematuria, normocytic anemia and borderline hypertension. The patient also had bilateral cataracts and nonspecific complaints of joint pains and was taking symptomatic treatment for all of these problems. The cause of her death was not immediately apparent

Subject No. 16 (U). This was a 67-year old male who was last seen for a visit in March 1992. He had a history of myocardial infarction, hypertension, and diabetes mellitus, and was being treated with Micronase $5 \mathrm{mg}$ daily and Vasotec $5 \mathrm{mg}$ daily. His diabetes was inadequately controlled and he had multiple ulcerations over his extremities. During his last visit he was found to have a prominent abdominal aorta and was being referred to Majuro for an ultrasound. The immediate cause of his death is unknown.

Subject No. 17 (U). This was a 75-year old woman who had been seen in Miarch 1992 by the medical team. She was found to have out-of-control diabetes, increasing kidney function impairment and hypertension. In 1991, she was referred to Honolulu for persistent microscopic hematuria, which was found to be due to a renal calculus. A mammogram showed nipple retraction, and there were vascular calcifications in both breasts. The cause of her death is unknown.

Subject No. 18 (U). This was an 83-year old female who was last seen during the spring 1993 mission. Her past history inchuded colon cancer surgically corrected in 1985. She had negative colonoscopies in 1988. She was found to be unresponsive and to have massive urinary tract infection. She was treated with intravenous antibiotics and hydration, and then transferred to Majuro Hospital for contimued care. The inmediate canse of her death was unknown but presumed to be due to urosepsis and coma.

Subject No. 19 (R). This was a 78-year old male last seen in the fall of 1993 with a history of diabetes with ophthalmopathy. He also had a history of hypertension, hypertigiyceridemia, and positive Hepatitis B. The patient expired in 1994; immediate cause of deati is unimown.

Subject No. 20 (R). This 89-year old male was last seen in August 1994 at the Straub Clinic and Hospital He had colonic polyps, an abnormal thyroid ultrasound, a history of anemia, and hypothyroidism replacement with Synthroid. In April 1994, he also 
had a history of a CVA and aphasia. The patient expired in October 1994; the cause of his death is not known.

Subject No. 21 (R). This 75-year old female was last seen in 1994 during the fall mission. She had been taking Synthroid for hypothyroidism. She aiso had a history of Type II Diabetes Mellitus which was treated with Micronase. She was status post cerebral vascular accident. The patient expired in July 1995 , and the immediate cause of her death is not known.

Subject No. 22 (U). This patient was an 83-year old male, last seen during the fall 1993 mission. He had a history of anemia, glaucoma, mild hypertension, and renal abnormalities. His past history also included aortic stenosis and hypertriglyceridemia. The immediate cause of his death is not known.

Subject No. 23 (U). This 77-year old male patient had a history of chronic obstructive lung disease and hematuria, and had been seen at the Straub Clinic and Hospital for abdominal aortic aneurysm. He had a urinary cytology which showed no evidence of carcinoma. He was extensively worked upon with abdominal CT and renal ultrasound at the Straub Clinic and Hospital, and the only abnormality detected was a large aneurysin. No cause of death was identifiable.

Subject No. 24 (U). This female was born in 1923 and probably died in 1992 . The patient was a 69 year old female who had a history of iron deficiency anemia, dementia, organic brain syndrome, and hypothyroidism. The patient was homebound, and had been in that condition for several home visits, the last one in 1992. The immediate cause of her death is unknown.

Subject No. 25 (U). This 62-year old female was an unknown diabetic for many years with a history of back and knee pain, as well as hemorrhoids. Her diabetes had been well controlled, and the patient's pain symptoms were relieved with analgesic therapy. The patient was last seen in September 1993, and the immediate cause of her death is unapparent.

Comparison sroup (All volunteer comparison patients were from Rongelap):

Subject No. 1. This was a 56-year female last seen during the spring 1996 mission. She had a history of congestive heart faihure, atrial fibrillation, microhematuria, and diabetes mellitus. The patient had aortic stenosis and regurgitation with angina, and had required cardiac surgery for valvular replacement in 1980. The problem with the congestive heart failure appeared to be worsening when she was seen during the mission. An electrocardiogram showed atrial fibriliation, and the chest $x$-ray showed congestive cardiomegaly with pleural effusions bilaterally. The patient was treated during the mission, and then referred to the RMI Government for continued care. The immediate cause of her death was unknown.

Subject No. 2. This was an 84-year old female who was seen during the spring 1993 mission. She had a history of anemia of non-specific origin, a heart murmur and elevated cholesterol levels. She also had a history of diabetes mellitus and mild renal impairment. She was treated with Micronase $5 \mathrm{mg}$ daily, and symptomatic treatment for analgesia with Tylenol. The immediate cause of her death was unknown.

Subject No. 3. This was a 62-year old woman with a previous history of anemia and nonspecific joint pains, as well as diabetes mellitus with adequate control. She had been treated with Micronase (4 tablets twice a day) and multivitamins. She had no abnormalities noted on her most recent thyroid ultrasound. Flexible sigmoidoscopy done during that visit was normal. There was no immediate known cause of death noted.

Subject No. 4. This was an 81-year old woman with a history of diabetes mellitus and status post thyroid carcinoma treated surgically in 1982 . It was an occult papillary carcinoma. She had been treated with Micronase $5 \mathrm{mg}$ daily and Synthroid $100 \mathrm{mcg}$ daily. She also was known to have nonspecific joint pains and a history of anemia. She was last seen in March 1996, and treated with the above mentioned medications. She also had elevated creatinine, and high triglycerides and cholesterol. The immediate cause of death is not known. She is known to have expired in September 1996.

Subject No. 5. This was a 70-year old male who had a previous history of hypothyroidism diagnosed in 1992. He was being treated with Synthroid $200 \mathrm{mcg}$ daily. Routine thyroid ultrasound indicated a multinodular gland with some retrosternal extension. FNA was done on one of the nodules, and this was nōadiagñostic. The pautent also had a history of cataracts in both eyes, and had a routine sigmoidoscopy in 1992 which was normal. The immediate cause of his death is not known. 
Subject No. 6. This was a 73-year old female who was last seen during the spring 1985 mission. No other records were available after 1985 to make a satisfactory assessment of her medical condition. She was, however, known to be hypertensive, and was treated with Hydrochlorthizine. There is no known cause of death.

Subject No. 7. This was a 47-year old woman who was last seen during the fall 1995 medical mission. She had a history of diabetes mellitus treated with Micronase. She also had a history of fungal infections and microhematuria. Her thyroid function tests were normal and her last known blood tests for serum chemistries were normal. She also had iron deficiency anemia, a urinary tract infection, and multiple joint pains. The immediate cause of her death is not known.

Subject No. 8. This was an 82-year old male who was last seen during the fall 1993 mission. He had progressive anemia and refused to have bone marrow testing. A house call was made to evaluate his medical status. He was found to be unresponsive during his visit but moved all his extremities. He had some cough and fever for about a month prior to the home visit. The impression was that of severe cachexia secondary to his age, and the family decided against transporting the patient for further care at a hospital. The patient reportedly died soon after the home visit.

Subject No. 9. This was a 62-year old female who was last seen during the Medical mission in March 1993. She had a history of diabetes mellitus which was treated with Micronase $5 \mathrm{mg}$ daily. She also had nonspecific joint pains, as well as vulvulitis. Her laboratory tests during the last visit indicated no specific abnormalities. She was later admitted to Majuro Hospital in a coma of 24-hour duration and sepsis. She was eventually diagnosed with meningitis which was reported to be the cause of her death on the death certificate.

Subject No. 10. This was a 70-year old male seen at Ebeye Hospital during the spring 1994 mission. He had been admitted to Ebeye Hospital with a history of osteomyelitis, and sepsis. He also was a known diabetic and was being treated with Micronase $5 \mathrm{mg}$ daily. He had a prior history of thrombocytopenia of unknown etiology. During the hospital visit he was given Ciprofloxin $500 \mathrm{mg}$ twice a day and was given a renewal of his Micronase prescription. The inmediate cause of his death was not known but presumed to be sepsis due to osteomyelitis.

Subject No. 11. This was a 53-year old male who was last seen during the 1994 fall mission. He expired in 1995. He had a history of cerebral vascular accident which occurred several years ago, and he had residual left-sided hemiparesis. He had impaired renal function, and a history of anemia. He also had a history of hypertension, which was controlled with Nifedipine 10 $\mathrm{mg}$ four times daily. The patient had no thyroid abnormalities. The immediate cause of his death was not known.

Subject No. 12. This was a 70-year old male who was last seen during the fall 1995 mission. The patient had a history of multiple thyroid nodules which were diagnosed on thyroid ultrasound. These were benign. He also had a history of hypertension, bronchial asthma with chronic obstructive lung disease, and congestive cardiac failure. He also had Type II Diabetes Mellitus associated with obesity. The patient expired in 1996 and the immediate cause of his death was not known.

Subject No. 13. This was a 51-year old female last seen during the fall 1993 mission. She had a history of urinary tract infection, Diabetes Mellitus with neuropathy, degenerative arthritis of the cervical spine, and a class III PAP smear. She had a painless mass in the right breast which was most likely of inflammatory origin. She was referred to the 177 Health Care Program for treatment and excision of the mass. The immediate cause of her death was unknown. She expired in 1996; since 1994, she had not been attending follow-up visits to the Medical Program.

Subject No. 14. This was a 71 -year old female last seen during the fall 1992 mission during a home visit. During the last mission that she was seen, she was found to have Type II Diabetes Mellitus (she took insulin for a short time, then switched to oral agents), hypertension, hearing difficulty, and bilateral cataracts. She was treated with Micronase $5 \mathrm{mg}$ daily and Vasotec $10 \mathrm{mg}$ daily. She subsequently refused other visits and expired in 1995. The immediate cause of her death is unknown. 


\section{BIBLIOGRAPHY}

Cronkite, E.P., Bond, V.P., Conard, R.A., Shulman, N.R., Farr, R.S., Cohn, S.H., Dunham, C.L., and Browning, L.E. 1955. Response of human beings accidentally exposed to significant fallout radiation. J. Amer. Med. Assoc. 159:430434.

Lessard, E., Miltenberger, R., Conard, R., Musolino, S., Naidu, J., Moorthy, A., and Schopher, C. 1985. Thyroidabsorbed Dose for People at Rongelap, Utrik and Sifo on March 1, 1954. BNL 51882.

Conard, R.A., Meyer, L.M., Rall, J.E., Lowery, A., Bach, S.A., Cannon, B., Carter, E.L., Eicher, M., and Hechter, H. 1958. March 1957 Medical Survey of Rongelap and Utrik People Three Years after Exposure to Radioactive Fallout. BNL 501 (T-119).

Howard, J.E., Vaswani, A.N., and Heotis, P.1997. Thyroid Disease Among the Rongelap and Utrik Population -- An Update. Health Phys. 73(1):190-198.

LaRosa, E.L., Ludo, L., Giuffrida, D., Gullo, D., Vigneri, R., and Belfiore, A. 1995. Levothyroxine and potassium iodide are both effective in treating benign solitary solid cold nodules of the thyroid. Ann. Intern. Med. 122:1-8.

Tan, G.H., Gharib, H., and Reading, C.C. 1995. Solitary thyroid nodule. Arch. Intern. Med. 155:2418-2423.

Mazzaferri, E.I. and Jhiang, S.M. 1994. Long-term impact of initial surgical and medical therapy on papillary and follicular thyroid cancer. All. J. Med. 97:418. 


\title{
Epilogue
}

by

\author{
E.P. Cronkite, M.D.
}

On March 1, 1954 following a detonation of a thermonuclear bomb, Rongalap and Utrik inhabitants, as well as American Servicemen were exposed to fallout. Several Marshallese had sufficient fallout material on their skins to produce Beta burns. The burns healed leaving scars in some individuals. There were significant decreases in white blood cell and platelet counts which ultimately returned to normal. There had been nausea, vomiting and diarrhea in some of the Marshallese which was not reported in the exposed Americans. The team that observed the exposed persons returned to the US when it became evident that the exposed persons were recovering from the effects of the fallout radiation.

On July 12-13 1954, Dr. John Bugher, Director, Division of Biology and Medicine of Atomic Energy Commission convened a meeting of all personnel that had observed the Rongalap and Utrik inhabitants caught in radiation fallout in order to discuss the future management of these Marshallese patients. He made it clear that the DBM-AEC would be responsible for the future observation and care of the Marshallese that had been exposed on Ailinginae, Rongerik and Utrik Atolls and that the Department of the Interior was responsible for general medical surveillance of the Marshallese on other atolls. It was decided that V.P. Bond would lead a team to survey the status of the Rongalap and Utrik inhabitants of the above atolls six months after the accident and that E.P. Cronkite lead a team 12 months after the accident. Dr. R.A. Conard assumed responsibility in 1956, for direction of the continuing Marshallese Miedical Program involving those individuals exposed on Ailinginae, Sifo, Rongelap and Utrik under auspices of BNL. For 25 years, Dr. Conard guided the program with skill and diplomacy. There were some turbulent times, when through misunderstanding of the role of the BNL team, the Marshallese became uncooperative largely as a result of political problems.

There is no question that the radiation was responsible for skin burns, epilation, temporary suppression of hemopoiesis, thyroid hypofunction, thyroid tumors and probably responsible for the fatal case of acute leukemia. One can never be absolutely certain sirice it is not possible to tell the difference between spontaneous leukemia and radiationinduced leukemia. Based upon the extensive data collected in Japan on the survivors from the atomic bombs at Hiroshima and Nagasaki, it is most unlikely that further radiation effects will be observed in the Rongalap and Utrik inhabitants caught in radioactive fallout. However, there are problems traceable to the nuclear bomb testing in the Marshall Islands. 
Appendix A

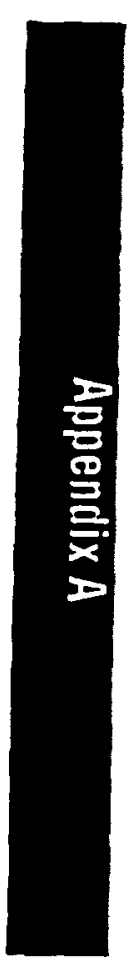




\section{PROFESSIONAL STAFF PARTICIPATING IN THE} 1992-1996 MARSHALL ISLANDS SURVEYS

NAMEJSPECIALTY

\section{CARDIOLOGY}

Maj Janet Hays, MD

\section{DERMATOLOGY}

Richard Ostreicher, MD

$\mathrm{S} / 92$

PARTICIPATING SURVEY

$\mathrm{S} / 92$

F/93

Douglas Binder, MD

Eric Lindborg, MD

Steven Mehaffey, MD

\section{ENDOCRINE}

LaVonne Berg. MD

$\mathrm{S} / 92$

S/95

S/94

F/95, S/96

Robert Blank, MD

Col Michael Bornemann, MD

\section{AFFILIATION}

Senior Cardiology Fellow Brook AMC

San Antonio, TX

Sr Resident, Dermatology NY Univ Med Center NYC, NY

Resident, Emergency Med Bronx Municipal Hosp Ctr NYC, NY

Chief of Staff

Kwajalein Hospital

Kwajalein, $\mathrm{MH}$

Staff Physician

Kwajalein Hospital

Kwajalein, $M H$

Fellow, Endocrinology

Case Western Reserve Univ Cleveland, $\mathrm{OH}$

Fellow, Endocrinology Rockefeller Univ NYC, NY
Chief, Endocrinology Dept of Medicine Tripler AMC Honolulu, $\mathrm{HI}$ 
Assoc Chief of Staff

VA Medical Center

Cleveland, $\mathrm{OH}$

CPT Lloyd Hancock, MD

Maj Gregory Hughes, MD

Mark Lakshmanan, MD

S/93

F/96

F/94

Lawrence Parker, MD

Maj R. Michael Tuttle, MD

Ashok Vaswani, MD

CMD Ann Yoshihashi, MD

S/95

F/96

$F / 92$
Asst Chief, Endocrinology Eisenhower Army Med Ctr Fort Gordon, GA

Staff Endocrinologist Tripler AMC

Honolulu, $\mathrm{HI}$

Senior Instructor Dept of Endocrinology Metro Health Med Ctr Cleveland, $\mathrm{OH}$

Professor of Medicine East Carolina Univ Sch of Med

Greenville, NC

Asst Chief, Endocrinology VA Med Ctr Long Beach, CA

F/93, F/96

Chief Endocrinology Walter Reed AMC Washington, DC

Consulting Endocrinologist, MIMP

Asst Prof of Medicine, SUNY, NY

Fellow, Endocrinology National Naval Med Center Bethesda, MD

Director, Indian Health Service, PHS

Albuquerque, NM

Kevin Cook, MD, MPH

Staff Physician Kwajalein Hospital Kwajalein, MH 
Michael Bliss, MD

Peter 댄lls, MD

Wayne Lucas; MD

F/96

$\mathrm{S} / 92, \mathrm{~F} / 92$

William Adams, MD

Jean Howard, MD

INFECTIOUS DISEASES

Dina Toren, MD

$F / 92$

S/92, F/92, S/93, F/93,

S/94, F/94, S/95, F/95,

S/96, F/96

S/93

S/94

Maj Benjamin Berg, MD

F/94

Michael Hamilton, MD, MPH

Thomas Minor, MD

S/92, F/95
Prof of Medicine

Boston City Hospital

Boston, MA

Acting Dir, Gastroenterology

SUNY, Stony Brook

Stony Brook, NY

Fellow, Gastroenterology

Boston City Hospital

Boston, MA

Medical Dir, MIMP (to 1992)

Brookhaven National Lab,

Upton, NY

Hematology/Oncology Medical Dir, MilMP (from 1993) Brookhaven National Lab, Upton, NY

Dept of Infectious Disease Fellow, NY Univ Med Center NYC, NY

Chief of Staff Yale School of Med New Haven, CT

Staff Pulmonologist

Dept of Medicine

Tripler AMC, Honolulu, HI

Clinical Asst Prof of Medicine Duke Univ Med Ctr

Durham, NC

Fellow, Medicine

Mayo Clinic

Rochester, MN 


\section{NEPHROLOGY}

Staff Nephrologist

Dept of Medicine

Brook AMC

Houston, TX

NUCLEAR MEDICINE

John Harbert, MD

F/95

Prof Emeritus, Nuc Med Georgetown University McLean, VA

Advisor to Presidential Committee on Radiation

Henry Royal, MD

S/96

Prof of Radiology Mallinckrot Inst

St. Louis, MO Member of Presidential Committee on Radiation

\section{OB/GYN}

Stuart Abrahams, MD

$F / 95$

Frank Anderson, MD, MPH

F/93

Lauren Brown, MD

S/93, S/94, S/95

Private Practice, GYN

Greensboro, NC

Fellow/Instructor, GYN John Hopkins Univ Baltimore, MD

Pediatric Gynecologist Children's Hospital Boston, MA

Pui Chun Cheng, MD

S/94

Richard Gallagher, MD

F/96

Col Samuel Heth, MD

F/94

Robert Holland, MD

F/95

Chief Resident, GYN

Stony Brook Univ

SUNY, Stony Brook, NY

Private Practice, GYN

Concord, MA

Staff Physician, GYN Tripler Army Med Ctr Honolulu, $\mathrm{HI}$

Staff Physician, GYN Mountainview Woman's Health

Granóview, WA

William Inkret, MD

F/96

Private Practice, GYN Denver, CO 
Rochelle Mathieu, RN, NP

Leonard Schonberg, MD

S/96

John Tucker, MD

S/92

Marina Torbey, MD

S/92

Maj Mary Zozulin, MD

S/95

S/93, S/94

Donald Paglia, MD

\section{PATHOLOGY}

\section{PULMONARY}

Herman M. Blaton, MD

S/92

Robert Fallat, MD

F/93

Maj Joseph Kem, MD

F/93

F/94
Staff Physician, GYN

Carolina Permanente Med

Grp

Raleigh, NC

Private Practice, GYN

Hilo, HI

Private Practice, GYN

Helena, MT

Asst Clinical Prof of GYN Harlem Hospital NYC, NY

Attending Physician, GYN Abert Einstein College of Medicine

Bronx, NY

Staff Physician, GYN US Air Force MC Grand Forks, ND

Prof of Pathology UCLA

Los Angeles, CA

Chief, Pulmonary Service Brooke AMC

San Antonio, TX

Dir of Pulmonary Research California Pacific Med Ctr San Francisco, CA
Staff Physician, Pulmonary Div Madigan Army Center, Tacoma, WA 


\section{RADIOLOGY}

William Brant, MD

F/94

Maj Allen Chantelois, MD

$\mathrm{S} / 92$

LCDR Daniel Davis, MD

F/96

CPT Michael Freckleton, MD

S/95

CPT Walter Goff II, DO

F/94

Col Chris Jennings, MD

S/96

CMD David Lawrence, MD

S/94

LTCD Robert McFarland, MD

S/96

Maj David May, MD

S/95

Philip Moyers, MD

F/95

F/95
Assoc Prof of Radiology Univ of CA - Davis Davis, CA

Staff radiologist Fitzsimmons ÂM̂C Aurora, CA

Diagnostic Radiologist Dept of Radiology National Naval MC Chesapeake, VA

Chief, Outpatient Radiology Air Force MC Lackland, TX

Chairman, Radiology Dept Naval MC San Diego San Diego, CA

Staff Radiologist Tripler Army Med Center Honolulu, $\mathrm{HI}$

Director, MRI National Naval Med Ctr Bethesda, MD

Staff Radiologist San Diego Naval Med Center San Diego, CA

Staff Radiologist Wifford Hall AFB Lackland, CA

Fellow, Radiology \& Nuc Med Barnes Hospital

St. Louis, MO

Chair of Radiology Univ of Texas Health Center Tyler, TX 
Virginia Toombs, MD

Philip Wiest, MD

\section{SURGEON}

Earl Thomhill, MD

\section{NURSES}

Altina Anien

Toltha Arelong

Sandy Balos

Marlene Brady

Kathy Campbell

Trudy Campbell

Lynda Firment

Deborah Greenhill

Reine Heine

Aurelia Inkret

Stanley Jacob

Helen Jetnil

Nennet Joel
F/94

S/96

F/96

F/94

F/96

F/93, F/96

F/92

F/95

F/94

$\mathrm{S} / 92, \mathrm{~F} / 92$

S/93

$\mathrm{S} / 94$

S/94

S/95
Private Practice, Radiology

Palo Alto

California

Asst Prof Radiology

VA Medical Ctr

Albuquerque, NM

Staff Physician

Kwajalein Hospital

Kwajalein, MH

Majuro Hospital

Majuro, MH

Majuro Hospital

Majuro, MH

Majuro Hospital

Majuro, MH

Kwajalein Hospital

Kwajalein, MH

Kwajalein Hospital

Kwajalein, MH

Kwajalein Hospital

Kwajalein, MH

DOE

Washington, DC

Kwajalein Hospital

Kwajalein, MH

Majuro Hospital

Majuro, MH

Private Practice

Denver, Co

Ebeye Hospital

Ebeye, MH

Majuro Hospital

Majuro, MH

Majuro Hospital

Majuro, MH 
Kelly Johnson

Leslie Kirkham

F/95

Clementina Lalimo

F/96

Tinar Lalimo

S/93

Rosebeth Lang

S/96

Risen Lomae

Utena Marshall

Tina Naisher

No Phillips

Linda Puchon

Nanik Rantak

Patricia Rembert

Albina Riklon

Patricia Robins

Ivy Springer

Caroline Tuman

Mary Ulyat
F/94

F/9, S/95

F/95

S/93

F/93

S/93

S/95

S/92, F/92

F/95

F/94, F/96

F/96

S/96
Tripler AMC

Honolulu, $\mathrm{HI}$

Kwajalein Hospital

Kwajalein, $\mathrm{MH}$

Majuro Hospital

Majuro, MH

Majuro Hospital

Majuro, MH

Majuro Hospital

Majuro, MH

Majuro Hospital

Majuro, $\mathrm{MH}$

Majuro Hospital

Majuro, $\mathrm{MH}$

Majuro Hospital

Majuro, $\mathrm{MH}$

Majuro Hospital

Majuro, MH

Kwajalein Hospital

Kwajalein, MH

Majuro Hospital

Majuro, MH

Kwajalein Hospital

Kwajalein, MH

Armer Ishoda Hospital

Majuro, MH

Dept of HHS/Public Health Service, Bethesda, MD

Kwajalein Hospital

Kwajalein, $\mathrm{MH}$

Resident Nurse

Walter Reed AMC

Washington, DC

Private Nurse

Upton, NY 
PHARMACY

NAME

Jiri Cizinsky

$S / 94, S / 96$

Consultant, MIMP

Upton, NY

Blanka Cizinsky

S/96

Pharmacy Assistant

BNL, Upton, NY

\section{ADMINISTRATION}

NAME

Peter Heotis, MPS

$S / 92, F / 92, S / 93, F / 93$, $S / 94, F / 94, S / 95, F / 95$, $\mathrm{S} / 96, \mathrm{~F} / 96$

Wiliiam Scott

$\mathrm{S} / 92, \mathrm{~F} / 92$

Admin, MIMP (from 1993)

BNL, Upton, NY

Admin, MiMP

BNL, Upton, NY

\section{TECHNICIANS}

\section{NAME}

Robert Brown, Tech

Linda Cavaliere, RT

Helmer Emos, Tech

$S / 92$ - F/96

F/93, S/94, F/94, S/95,

F/95, S/96, F/96

$F / 95$

Lee Harris, RT

$F / 92, S / 93, F / 93$

John Heinrichs, MS

$\mathrm{S} / 92$

S/92, F/92, S/93, S/94

William Lehman, RT

$\mathbf{S} / 92$

S/94

Tonya Sheppard, RT

S/94 - F/96

S/92, F/92, S/93, F/94 - F/96

MIMP

BNL, Upton, NY

Medical

BNL, Upton, NY

MIMP, BNL

Ebeye, MH

Honolulu, $\mathrm{HI}$

Medical

BNL, Upton, NY

Medical

BNL, Upton, NY

Stony Brook Univ

Stony Brook NY

Sacramento, CA

Long Island, NY

BNL, Retired

Crystal River, FL 
TRANSLATORS

Capelle DeBrum, Translator

Elsa Patton, Translator

Kosang Mitzutani

Sebio Shoniber

Pamela Hazel

Max Helkena

Estella Leviticus

Heddleson Jeadrik

Marie Laik

Linda Hall
$F / 93-F / 96$

F/96

$\mathrm{S} / 92$

$\mathrm{S} / 92, \mathrm{~S} / 93, \mathrm{~F} / 93, \mathrm{~F} / 94$

F/93

F/93

S/95

S/96, F/96

S/96, F/96

F/96
Bechtel Nevada

Honolulu, $\mathrm{HI}$

Kwajalein, MH

Majuro, MH

Majuro Hospital

Majuro, MH

Kwajalein, MH

Majuro Hospital

Majuro, $\mathrm{MH}$

Majuro Hospital

Majuro, MH

Ebeye Hospital Ebeye, MH

Bechtel Nevada, Hi

Kwajalein, MH 
Appendix B

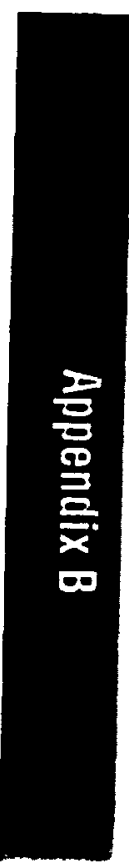


Individual patient (Marshallese)) laboratory data collected during 1992 through 1996 medical surveys. (Identification numbers 1 to 86 belong to exposed persons of Rongelap and Ailingnae; numbers beginning at 2102 belong to the Utirik exposed: numbers from 805 through 1578 belong to the Comparison groupl.

Abbreviations :

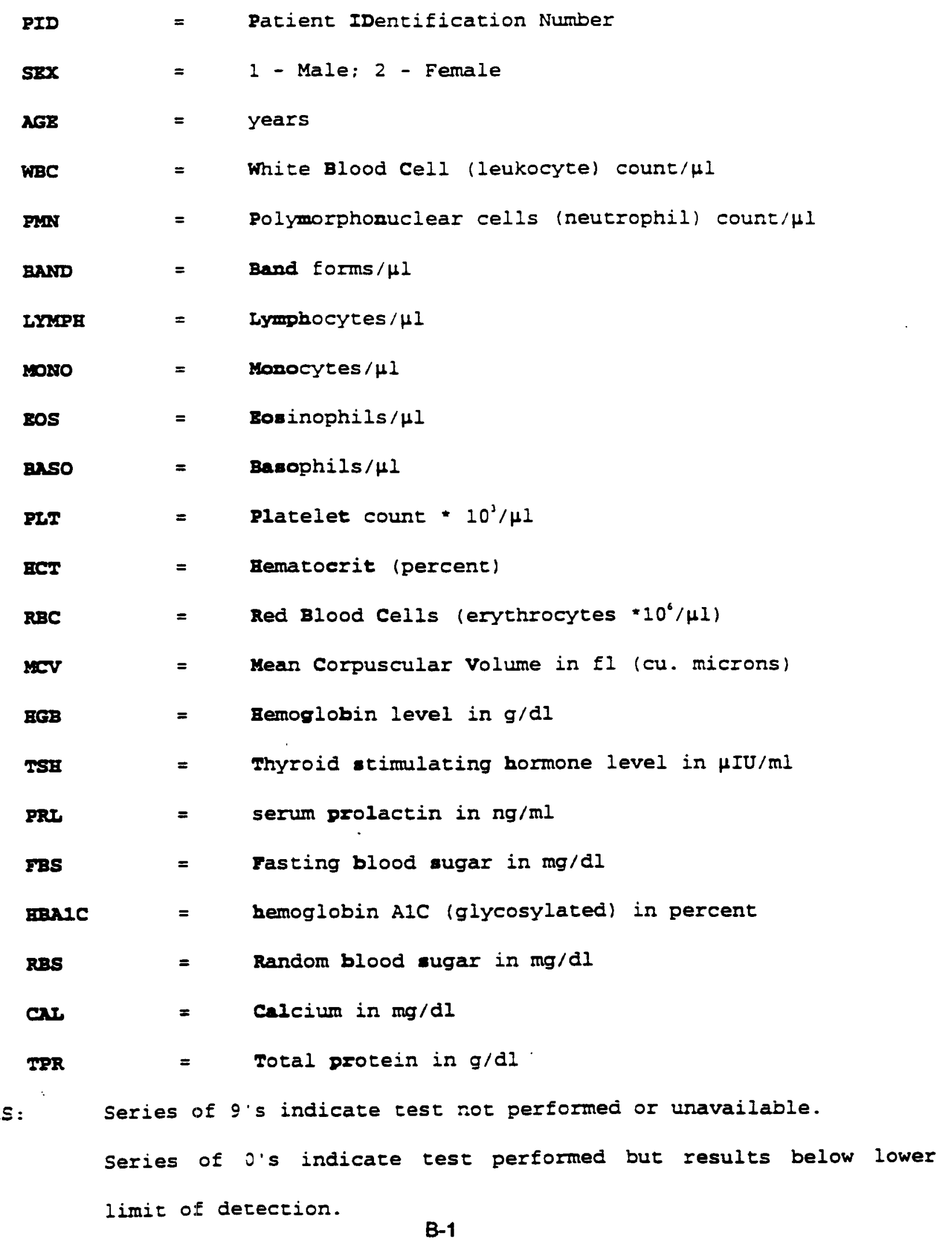


COMPUTER LISTINo OF 1992 RAH DATA

\begin{tabular}{|c|c|c|c|c|c|c|c|c|c|c|c|c|c|c|c|}
\hline PID & $E X$ & $A G E$ & WBC & PMN & BAND & LYMPH & HONO & Eos & BAsO & PLT & HCT & RBC & MCV & HGD & TSH \\
\hline $\begin{array}{l}2 \\
3\end{array}$ & $\begin{array}{l}1 \\
1\end{array}$ & $\begin{array}{l}39 \\
39\end{array}$ & 11100 & $\begin{array}{l}6210 \\
5130\end{array}$ & $\begin{array}{l}0 \\
0\end{array}$ & $\begin{array}{l}1890 \\
3990\end{array}$ & $\begin{array}{r}90 \\
570\end{array}$ & $\begin{array}{r}810 \\
1254\end{array}$ & $\begin{array}{r}0 \\
114\end{array}$ & $\begin{array}{l}218 \\
233\end{array}$ & & 97 & $\begin{array}{l}96.3 \\
89.3\end{array}$ & $\begin{array}{l}14.6 \\
15.3\end{array}$ & $\begin{array}{r}2.30 \\
999.99\end{array}$ \\
\hline 4 & $i$ & 76 & 11800 & 2496 & 116 & 590 & 1062 & & 0 & 207 & 11.3 & 5.23 & 84.7 & 15.3 & .90 \\
\hline 5 & 1 & 39 & 5700 & 2394 & 57 & 2337 & 342 & 456 & 114 & 250 & 45.6 & 4.57 & 100.0 & 13.3 & 999.99 \\
\hline 6 & 1 & 39 & 7200 & 4680 & 0 & 2304 & 144 & 72 & 0 & 265 & & 4.93 & & & 3.12 \\
\hline 7 & 1 & 72 & 9300 & 3906 & 93 & 3255 & 465 & 1088 & 93 & 314 & 39.2 & 4.33 & 90.6 & 13.8 & 999.99 \\
\hline 8 & 2 & 10 & 12600 & 5796 & 0 & 6174 & 126 & 378 & 126 & 305 & 39.0 & 1.16 & 93.7 & 14.4 & 4.33 \\
\hline 9 & 1 & 58 & 8000 & $: 640$ & 0 & 2880 & 160 & 320 & 0 & 220 & & & 90.0 & & 2.90 \\
\hline 14 & 2 & 62 & 7800 & 9368 & 0 & 3276 & 78 & 78 & 0 & 270 & 39.1 & 3.05 & 102.0 & & 1.90 \\
\hline 15 & 2 & 45 & 9100 & 4277 & 0 & 3549 & 728 & 546 & 0 & 316 & 40.6 & 1.35 & 93.1 & 13.6 & 11.50 \\
\hline 16 & 1 & 78 & 5100 & 2091 & 0 & 1785 & 153 & 969 & 102 & 219 & 38.6 & 5.29 & & & .74 \\
\hline 17 & 2 & 41 & 6800 & 4080 & 0 & 1632 & 541 & 544 & 0 & 267 & 37.6 & 1.32 & 87.1 & 13.3 & 11.70 \\
\hline 18 & 2 & 59 & 5100 & 2805 & 0 & 1785 & 153 & 255 & 102 & 215 & 39.0 & 4.24 & 92.0 & 12.6 & 1.60 \\
\hline 19 & 1 & 43 & 7.200 & 5400 & 0 & 1224 & 504 & 72 & 0 & 200 & 46.5 & 6.21 & 74.9 & 15.3 & 999.99 \\
\hline 20 & 1 & 44 & 5900 & 3009 & 0 & 1829 & 177 & 767 & 118 & 260 & & 5.12 & & 15.6 & 2.80 \\
\hline 21 & 2 & 40 & 6100 & 32 & 0 & 17 & 61 & 488 & 0 & 276 & & 4.78 & 80.2 & .2 & 79.99 \\
\hline 23 & 1 & 12 & 7700 & 26 & 0 & 4004 & 46 & 539 & 0 & 287 & 45.5 & 5.28 & 86.1 & & 6.68 \\
\hline 24 & 2 & 51 & 6100 & 3172 & 0 & 27 & 61 & 183 & 0 & 282 & 43.6 & 5.02 & 86.8 & 5 & .10 \\
\hline 27 & 1 & 64 & 0 & 3519 & 0 & 20 & 483 & 690 & 138 & 225 & & 4.37 & 103.0 & & 2.10 \\
\hline 33 & 2 & 40 & 9000 & 39 & 0 & 36 & 270 & 900 & 270 & 341 & 41.2 & 4.52 & 91.1 & 1 & 35.10 \\
\hline 34 & 2 & 82 & 10500 & 6300 & 315 & 2100 & 735 & 1050 & 0 & 245 & & 2.98 & 108.0 & 0 & 5.70 \\
\hline 36 & 1 & 46 & 10 & 14 & 0 & 25 & 370 & 99999 & 99 & 231 & & 3.79 & & & 15.22 \\
\hline 37 & 1 & 58 & Do & 7474 & 202 & 1414 & 202 & 909 & 0 & 187 & 37.9 & 1.11 & .1 & 0 & 1.50 \\
\hline 39 & 2 & 52 & 0 & 3800 & - & 28 & 304 & 532 & 152 & 102 & & 1.27 & & & 1.60 \\
\hline 40 & 1 & 67 & 7000 & 42 & 140 & 18 & 14 & 630 & 0 & 279 & 36.6 & 1.10 & 89.3 & & 2.70 \\
\hline 4! & 1 & 79 & 5800 & 3364 & 0 & 1624 & 232 & 580 & 0 & 215 & 36.8 & 3.94 & 95.0 & 1 & 3.80 \\
\hline 42 & 2 & 41 & 5700 & 2907 & 0 & 2508 & 11 & 57 & 114 & 181 & & 3.92 & & 0 & .12 \\
\hline 44 & 1 & 42 & 5500 & 2475 & 0 & 2365 & 440 & 220 & 0 & 299 & 34.6 & 3.73 & 92.8 & 3 & 1.30 \\
\hline 45 & 2 & 70 & 99999 & 99999 & 9999 & 99999 & 9999 & 9999 & 99 & 999 & & 9.99 & 999.9 & .9 & .50 \\
\hline 87 & 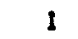 & 46 & 6800 & 3944 & 136 & 2126 & 272 & 201 & 68 & 217 & & 1.31 & & & 3.60 \\
\hline 48 & 2 & 43 & 5600 & 4032 & 0 & 11 & 28 & 56 & 56 & 225 & 1 & 4.39 & .0 & 3 & 19.99 \\
\hline 49 & 2 & 54 & 6800 & 30 & 0 & 3400 & & 204 & 136 & 299 & & 1.50 & .3 & 2 & 50 \\
\hline 53 & 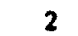 & 15 & 79 & 38 & 0 & 33 & 31 & 2 & 0 & 391 & & & & & 3.10 \\
\hline 61 & ? & 46 & 12500 & 8500 & 0 & 3375 & 250 & 250 & 99 & 286 & 37.9 & 1.37 & 86.7 & .8 & 7.10 \\
\hline $6 ?$ & 2 & -6 & 10500 & 99999 & 2999 & 99999 & 99999 & 99999 & 999 & 246 & & 4.11 & 88.2 & 1 & 999.99 \\
\hline 63 & 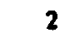 & 73 & 600 & 2772 & 0 & 3168 & 132 & 462 & 66 & 210 & & 4.33 & 90.6 & & 3.40 \\
\hline 6 & 2 & 68 & 5100 & 1734 & 0 & 3060 & 51 & 208 & 51 & 210 & 38.2 & 3.83 & 100.0 & 12.1 & 21.60 \\
\hline 65 & 2 & 33 & $5+00$ & 18 & 0 & 2214 & 162 & 972 & 162 & 265 & & & .9 & 11.6 & 99.99 \\
\hline 66 & ? & 67 & 74 & 22 & 148 & 4114 & 74 & 14 & D & 216 & & 4.34 & 0 & & 7.80 \\
\hline 6 & 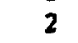 & 51 & 7400 & 466 & 0 & 18 & 44 & 44 & 0 & 245 & 41.1 & 3.99 & 103.0 & .9 & 17.30 \\
\hline 70 & 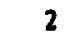 & 54 & 52 & 300 & 0 & 1716 & 208 & 156 & 52 & 205 & 36.5 & 4.20 & 87.0 & 12.1 & 6.80 \\
\hline 71 & 2 & 64 & 69 & 32 & 0 & 31 & 20 & 276 & 69 & 237 & 39.2 & 1.28 & .5 & .8 & 6.30 \\
\hline 72 & 2 & 45 & C & & 22 & 18 & 20 & 6 & 122 & 102 & & & & & 999.99 \\
\hline 73 & 1 & 56 & 43 & 23 & 0 & 12 & 4 & 215 & 0 & 200 & 4 & 4.85 & 95.6 & & 1.90 \\
\hline 7 & 0 & 53 & 93 & 50 & 186 & 28 & 372 & 837 & o & 223 & 14.7 & 5.02 & 89.1 & 15.2 & 3.30 \\
\hline 75 & 2 & 49 & 7500 & 3675 & 0 & 2925 & 300 & 450 & 150 & 257 & 40.2 & 4.15 & 90.3 & 13.1 & 11.80 \\
\hline 76 & 1 & 48 & 75 & 330 & 0 & 3225 & 450 & 450 & 75 & 180 & 44.6 & 1.82 & & & 999.99 \\
\hline 77 & 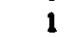 & 62 & 73 & 5 & 73 & 1314 & 292 & 146 & 73 & 263 & 45.0 & 5.03 & 89.5 & & 2.50 \\
\hline 78 & 2 & 73 & 5700 & 2337 & 57 & 3135 & 0 & 0 & 57 & 259 & 38.0 & 1.06 & 93.7 & .5 & 2.90 \\
\hline 79 & 1 & 77 & 6600 & 2904 & 0 & 2904 & 396 & 264 & 132 & 81 & 46.3 & 4.72 & .0 & & 1.40 \\
\hline 83 & 1 & 37 & 10200 & 199 & 0 & 3774 & 61 & 714 & 102 & 158 & & 1.87 & 97.3 & & 5.70 \\
\hline 85 & 1 & 37 & 7900 & 45 & 79 & 24 & 790 & 79 & 0 & 286 & 47.9 & 5.35 & 89.5 & 16.4 & 1.10 \\
\hline 86 & 2 & 37 & 7900 & 5372 & 0 & 1896 & 158 & 395 & 79 & 220 & 11.2 & 1.59 & & 12.7 & 3.10 \\
\hline 805 & 2 & 38 & 1200 & 99999 & 99 & 99999 & 999 & 999 & 99 & 324 & 37.6 & 4.62 & 81.1 & 12.2 & 9.99 \\
\hline
\end{tabular}


COMPUTER LISTING OF 1992 RAW DATA

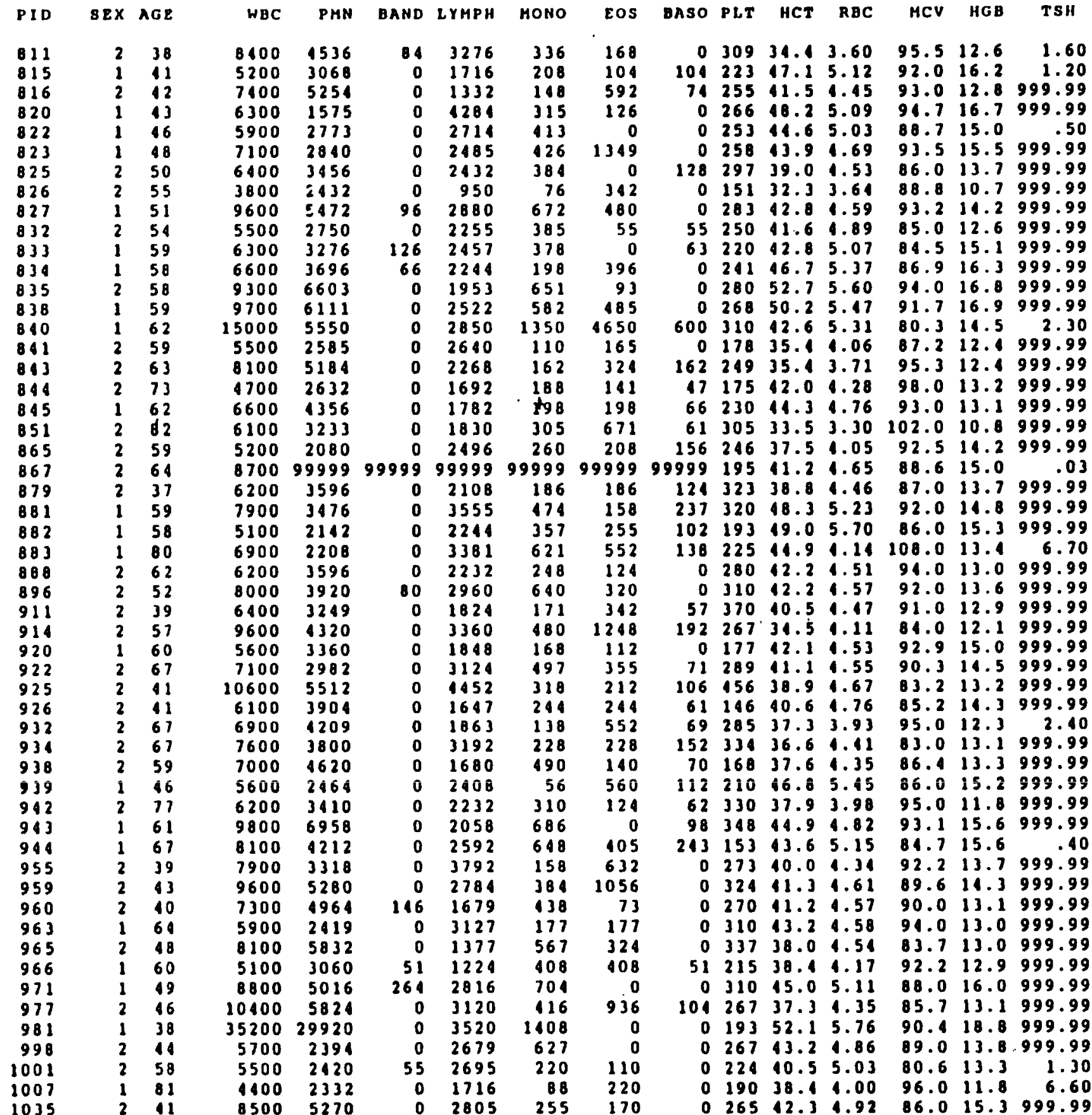


COMPUTER LISTINO OF 1992 RAW DATA

\begin{tabular}{|c|c|c|}
\hline PID & $8 E x$ & A \\
\hline 1036 & 2 & \\
\hline 1519 & 1 & \\
\hline 1520 & 2 & \\
\hline 1524 & 1 & \\
\hline 1525 & 2 & \\
\hline 1529 & 1 & \\
\hline 1541 & 2 & \\
\hline 1542 & 2 & \\
\hline 1546 & 1 & \\
\hline 1548 & 2 & \\
\hline 1549 & 1 & \\
\hline 1550 & 1 & \\
\hline 1552 & 1 & \\
\hline 1556 & 2 & 4 \\
\hline 1557 & 1 & 1 \\
\hline 1558 & 2 & 4 \\
\hline 1559 & 2 & 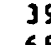 \\
\hline $\begin{array}{l}1560 \\
1564\end{array}$ & $\begin{array}{l}2 \\
2\end{array}$ & 6 \\
\hline 1567 & 2 & \\
\hline 1572 & 1 & \\
\hline 1573 & 1 & \\
\hline 1577 & 2 & \\
\hline 2102 & 1 & \\
\hline 2104 & 2 & \\
\hline 2105 & 1 & \\
\hline 2106 & 1 & \\
\hline 2107 & 2 & \\
\hline 2110 & 1 & \\
\hline 2111 & 2 & \\
\hline 2113 & 2 & 4 \\
\hline 2111 & 1 & 7 \\
\hline 2115 & 1 & 3 \\
\hline 2124 & 1 & 3 \\
\hline 2126 & 2 & 4 \\
\hline 2130 & 2 & 4 \\
\hline 2132 & 2 & 3 \\
\hline 2134 & 2 & 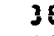 \\
\hline 2136 & 1 & 4 \\
\hline 2138 & 2 & 4 \\
\hline 2139 & 2 & 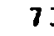 \\
\hline 2142 & 1 & 4 \\
\hline 2113 & 1 & 4 \\
\hline 2144 & 1 & 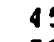 \\
\hline 2145 & 1 & 7 \\
\hline 2148 & 1 & 8 \\
\hline 2149 & 2 & 4 \\
\hline 2150 & 1 & 5 \\
\hline 2152 & 1 & 5 \\
\hline $2\lfloor 5\}$ & 1 & 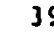 \\
\hline 2155 & 1 & 3 \\
\hline 2156 & 1 & 4 \\
\hline 2158 & 2 & \\
\hline 2160 & 2 & \\
\hline
\end{tabular}

\begin{tabular}{|c|c|c|c|c|c|}
\hline 180 & PMH & AND & LYMPH & MONO & eos \\
\hline $\begin{array}{l}7500 \\
5600 \\
7700\end{array}$ & $\begin{array}{l}1275 \\
3696 \\
1620\end{array}$ & $\begin{array}{r}75 \\
56 \\
0\end{array}$ & $\begin{array}{l}2700 \\
1288 \\
2695\end{array}$ & $\begin{array}{l}300 \\
336 \\
308\end{array}$ & $\begin{array}{r}75 \\
224\end{array}$ \\
\hline 10600 & 7314 & 212 & 2544 & 712 & 10 \\
\hline 6000 & 3180 & 0 & 1260 & 480 & 108 \\
\hline 10300 & 7210 & 0 & 2060 & 824 & 2 \\
\hline $\begin{array}{r}10600 \\
6400\end{array}$ & $\begin{array}{r}4452 \\
2752\end{array}$ & $\begin{array}{r}106 \\
0\end{array}$ & $\begin{array}{l}4982 \\
3136\end{array}$ & $\begin{array}{l}636 \\
320\end{array}$ & $\begin{array}{l}31 \\
19\end{array}$ \\
\hline 0300 & 5253 & 0 & 4120 & 824 & 10 \\
\hline 11600 & 74 & 232 & 2204 & 164 & 10 \\
\hline 8600 & 4386 & 0 & 2926 & 602 & 51 \\
\hline 10300 & 6180 & 0 & 3296 & 515 & \\
\hline 5400 & & $\begin{array}{l}0 \\
0 \\
0\end{array}$ & 24 & 162 & \\
\hline $\begin{array}{l}7700 \\
9200\end{array}$ & $\begin{array}{l}508 \\
552\end{array}$ & $\begin{array}{r}0 \\
92\end{array}$ & $\begin{array}{l}2156 \\
2576\end{array}$ & 460 & \\
\hline 10000 & 4400 & 0 & 4000 & 600 & 8 \\
\hline 11000 & 74 & 110 & 27 & 28 & 33 \\
\hline $\begin{array}{l}6600 \\
7500\end{array}$ & $\begin{array}{l}4092 \\
2475\end{array}$ & 0 & $\begin{array}{l}1980 \\
4350\end{array}$ & & 45 \\
\hline 7300 & 3212 & 0 & 3212 & 365 & 36 \\
\hline 7400 & 44 & 0 & 2072 & 370 & 37 \\
\hline 10700 & 54 & 0 & 3745 & 642 & 856 \\
\hline 2400 & 866 & 0 & 2108 & 372 & 1240 \\
\hline 9100 & 600 & 0 & & 455 & \\
\hline 6600 & 41 & 0 & 0 & 0 & 13 \\
\hline 8700 & 54 & 87 & 2088 & 261 & 78 \\
\hline 13000 & 59 & 0 & 3640 & 780 & 247 \\
\hline 15100 & 81 & 0 & 4832 & 90 & 105 \\
\hline & 43 & 0 & & 426 & 284 \\
\hline 10200 & 5506 & 0 & 3366 & 306 & 1020 \\
\hline 6600 & 24 & 0 & 36 & 0 & 31 \\
\hline 8200 & 59 & 0 & 8 & 344 & 34 \\
\hline 12100 & 66 & 0 & & 72 & 121 \\
\hline 9200 & 59 & 0 & & & \\
\hline 8300 & 39 & 83 & 39 & 166 & 0 \\
\hline 8200 & 492 & 0 & 22 & 246 & 1230 \\
\hline 5200 & 22 & $5 ?$ & & & \\
\hline 760 & $51 !$ & 76 & 12 & 38 & 608 \\
\hline 7900 & 418 & 0 & 30 & 2 & 474 \\
\hline 7800 & 18 & 0 & & & 15 \\
\hline 7000 & 31 & 0 & & 420 & 56 \\
\hline 10400 & 70 & 208 & 23 & 62 & 104 \\
\hline 6000 & 30 & 0 & & 12 & 60 \\
\hline 6500 & 3055 & 0 & 2860 & 390 & 19 \\
\hline 53 & 28 & 53 & 15 & 3 & 53 \\
\hline 600 & 270 & 0 & 28 & 240 & 18 \\
\hline & 266 & 0 & & 195 & 195 \\
\hline 7900 & 4661 & 0 & 2449 & 474 & 237 \\
\hline 7300 & 518 & 0 & 1533 & 365 & -7 \\
\hline 5800 & 3828 & 58 & & 252 & 390 \\
\hline 5600 & 3292 & 0 & 2016 & 280 & 112 \\
\hline 2700 & 113 & 27 & 1377 & 135 & \\
\hline 7200 & $\begin{array}{l}421 \\
345\end{array}$ & $\begin{array}{r}72 \\
0\end{array}$ & 19 & $\begin{array}{l}618 \\
256\end{array}$ & \\
\hline & & & & & \\
\hline
\end{tabular}

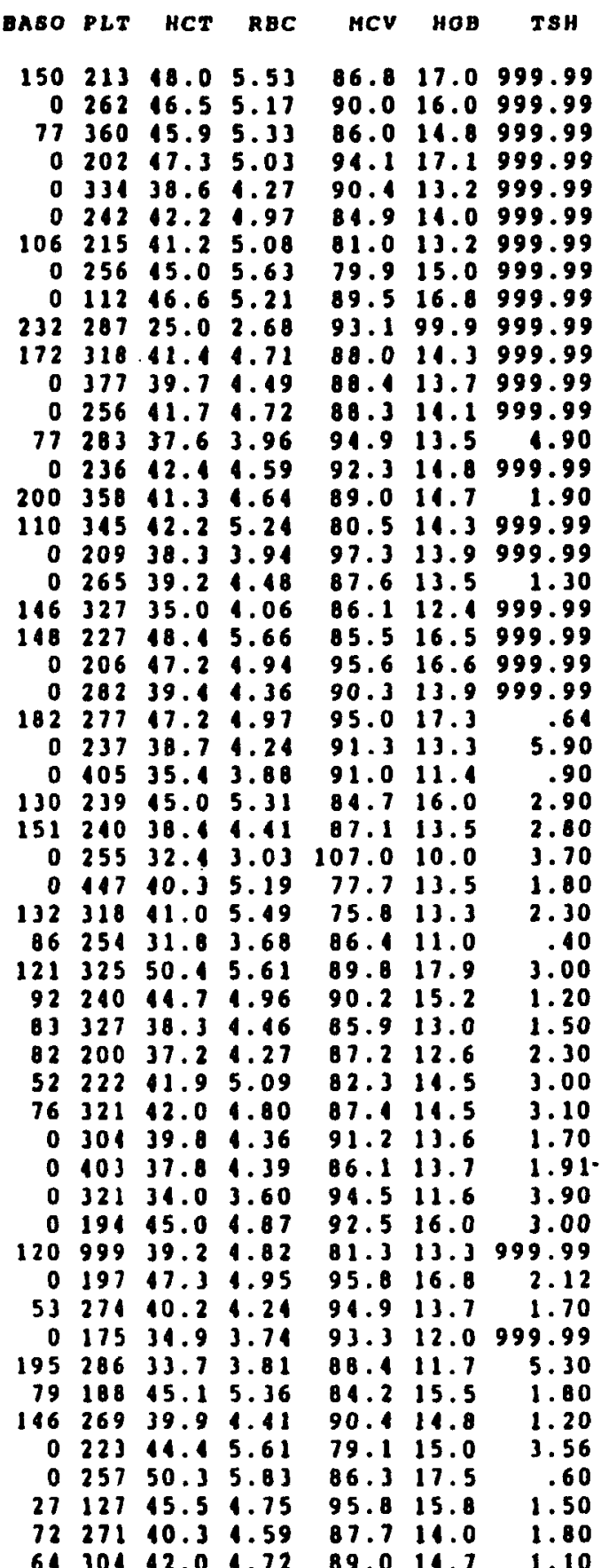


COMPUTER LISTINa OF 1992 RAH DATA

PID SEX AGE

$2162 \quad 270$

2166

216

2171

$\begin{array}{lll}21 & 72 \\ 2 & 174\end{array}$

2174
2176

2176

2180

2193

2195

2196

2197

2205

2206

2207

2208

2209

2210

2213
2215

2215
2216

2216

2217

222

2225

2226

222

2228

2229

2230

2231

2232

2233

2234

2235

2236

2237

2239

2244

2287

2250

2250

2251
2254

2256

2257

2261

2269

2271

2273
2274

2274
2277
$10100 \quad 7474$

$\begin{array}{ll}8900 & 7031 \\ 7000 & 2590 \\ 8600 & 3440\end{array}$

$\begin{array}{rr}8600 & 3440 \\ 6600 & 1554 \\ 10600 & 6572\end{array}$

$10600 \quad 6572$

$\begin{array}{ll}1400 & 1584 \\ 6300 & 1536\end{array}$

$5300 ? ? 86$

$6300 \quad 5: 29$

$7900 \quad 4303$

$8900 \quad 5340$

$6500 \quad 1160$

$7300 \quad 307$

81005022

$7000 \quad 3150$

$7000 \quad 4200$

$5700 \quad 2451$

$8300 \quad 3154$

8000
$13400 \quad 7772$

13400
16500
65345

$6400 \quad 1160$

$6300 \quad 3213$

$\begin{array}{rrrr}9600 & 5568 & 0 & 3264 \\ 99999 & 9999 & 99999 & 99999\end{array}$

100099993080

11700
6400
2752

$\begin{array}{ll}6400 & 2752 \\ 7700 & 3850\end{array}$

$7100 \quad 1260$

$8600 \quad 1644$

$6100 \quad 3477$

66003894

$9700 \quad 6014$

82005412

$5600 \quad 3304$

$6500 \quad 1160$

$5300 \quad 2173$

$8500 \quad 7250$

72003816

9300 62316

$9300 \quad 6231$

5300
6000
6200

62003348

$11300 \quad 7119$

$6100 \quad 4026$

$7400 \quad 3922$

54002538

$7000 \quad 2590 \quad 99999$

53002173

$1200 \quad 1464$

2343393

003200

2772

2838

01891

$66 \quad 2112$

2813

$0 \quad 2132$

o 1680

1040
2491

$170 \quad 1700$

2464

2160

1953

2173

1140
2170

3277

1464

2738

2214

o 2438

2088
MONO EOS

$\begin{array}{rr}404 & 0 \\ 267 & 0 \\ 210 & 0 \\ 430 & 2064 \\ 198 & 396 \\ 212 & 636 \\ 220 & 88 \\ 315 & 63 \\ 477 & 0 \\ 252 & 189 \\ 395 & 79 \\ 267 & 1124\end{array}$

$267 \quad 1424$

$\begin{array}{ll}195 & 130 \\ 365 & 219\end{array}$

$324 \quad 405$

280
$472 \quad 118$

0350

399570

83415

$100 \quad 400$

402
165

$512 \quad 192$

$126 \quad 252$

672
9999

264528

702585

$128 \quad 320$

$\begin{array}{ll}385 & 616 \\ 284 & 142\end{array}$

688

$366 \quad 366$

396

485
574

280

$212 \quad 371$

$510 \quad 1530$

$560 \quad 448$

$144 \quad 936$

$265 \quad 265$

$240 \quad 360$

$\begin{array}{ll}558 & 124 \\ 339 & 565\end{array}$

$366 \quad 183$

$222 \quad 444$

$378 \quad 162$

$\begin{array}{rr}560 & 70 \\ 124 & 159\end{array}$

$360 \quad 72$
BASO PLT hCT RBC

0
0 $7133.5 \quad 1.15$ $\begin{array}{lllll}0 & 325 & 12.9 & 1.05\end{array}$

25825241.84 .75

$0300 \quad 43.94 .92$

033649.45 .70

$\begin{array}{rrrr}176 & 249 & 42.8 & 4.52 \\ 0 & 245 & 32.5 & 3.35\end{array}$

53 $191 \quad 17.95 .46$

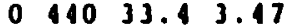

30038.41 .67

$\begin{array}{llllll}0 & 330 & 39.9 & 4.30\end{array}$

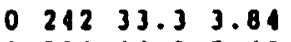

$\begin{array}{llll}0 & 234 & 4.4 .8 & 5.10 \\ 0 & 280 & 10.6 & 1.67\end{array}$

$\begin{array}{llllll}70 & 284 & 43.5 & 5.25\end{array}$

$\begin{array}{lllll}236 & 407 & 35.3 & 4.08\end{array}$

14051326.93 .28

$\begin{array}{llllll}0 & 281 & 10.1 & 4.56\end{array}$

$\begin{array}{llll}3 & 326 & 37.5 & 1.42\end{array}$

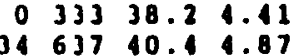

$\begin{array}{rlll}134 & 637 & 40.4 & 4.87 \\ 0 & 215 & 38.4 & 1.17\end{array}$

$6426539.7 \quad 1.34$

036535.63 .82

031631.83 .86

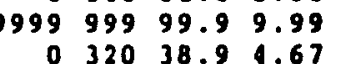

$\begin{array}{llll}0 & 320 & 38.9 & 0.67 \\ 0 & 999 & 39.2 & 1.27\end{array}$

$\begin{array}{llll}0 & 999 & 39.2 & .27 \\ 0 & 265 & 10.8 & 1.61\end{array}$

$\begin{array}{lllll}0 & 326 & 13.6 & 5.21 \\ 0 & 489 & 4.0 & 5.57\end{array}$

018051.15 .19

$0258 \quad 47.05 .06$

$132300 \quad 45.75 .14$

9739244.45 .09

039714.95 .26

$\begin{array}{llll}56 & 381 & 13.9 & 1.87\end{array}$

$\begin{array}{rrrr}0 & 323 & 38.5 & 1.36 \\ 53 & 235 & 35.4 & 3.76\end{array}$

5323535.43 .76

11230941.85 .03

14431544.95 .13

93 $36942.0 \quad 4.93$

$53366 \quad 37.5 \quad 4.71$

12018428.83 .12

23646.45 .64

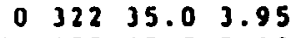

$\begin{array}{llll}61 & 257 & 47.5 & 5.13 \\ 0 & 273 & 47.9 & 5.10\end{array}$

$54 \quad 350 \quad 47.5 \quad 5.31$

030550.05 .85

10625548.45 .56

028534.95 .04

MCV HGB

TSH

11.31 .94

$\begin{array}{lll}8.0 & 13.6 & 1.50\end{array}$

40.10

$\begin{array}{lll}8.1 & 13.7 & 46.50\end{array}$

$\begin{array}{lll}17.4 & 2.17\end{array}$

$94.715 .0 \quad .80$

$97.010 .7 \quad 4.30$

$\begin{array}{lll}9.8 & 16.4 & 1.50\end{array}$

$\begin{array}{lll}2.2 & 13.0 & 1.40\end{array}$

\begin{tabular}{lll}
\hline & 12.8 & 20.90
\end{tabular}

$\begin{array}{lll}6.6 & 11.7 \quad 1.10\end{array}$

$2.911 .8 \quad 1.20$

86.914 .211 .20

$\begin{array}{lll}8.9 & 14.6 & 1.40 \\ 6.6 & 12.8 & 7.20\end{array}$

$1.99 .0 \quad 1.30$

$\begin{array}{lll}87.9 & 13.7 \quad 1.40\end{array}$

$\begin{array}{lll}84.813 .0 & 1.30\end{array}$

$\begin{array}{lll}6.6 & 12.6 & 6.90\end{array}$

$4.513 .9 \quad 1.10$

$\begin{array}{lll}9.2 & 13.2 & 1.10 \\ 9.5 & 14.1 & 3.50\end{array}$

$93.212 .2 \quad 1.80$

82.111 .53 .85

99.999 .93 .72

3.313 .12 .10

92.012 .91 .50

$3.711 .5 \quad 1.10$

$79.015 .1 \quad 1.50$

98.016 .1999 .99

$92.916 .1 \quad 1.80$

$\begin{array}{lll}92.0 & 15.7 & 3.70\end{array}$

$85.314 .6 \quad 7.50$

90.115 .122 .20

$68.213 .1 \quad .70$

$\begin{array}{lll}94.1 & 12.6 & 1.70\end{array}$

$\begin{array}{lll}9.1 & 10.9 & 1.20 \\ 3.1 & 14.0 & .30\end{array}$

$87.6 \quad 15.5 \quad 1.10$

85.214 .935 .10

$\begin{array}{lll}79.7 & 12.7 & 6.10\end{array}$

$\begin{array}{lll}84.2 & 9.8 & 1.50\end{array}$

$88.512 .6 \quad 1.00$

$92.516 .5 \quad 2.30$

$93.916 .6 \quad 1.30$

$\begin{array}{lll}89.0 & 15.2 \quad 2.70\end{array}$

$85.517 .5 \quad 1.12$

$\begin{array}{lll}69.2 & 10.8 & 1.37\end{array}$ 
COMPUTER LISTING OF 1993 RAW DATA

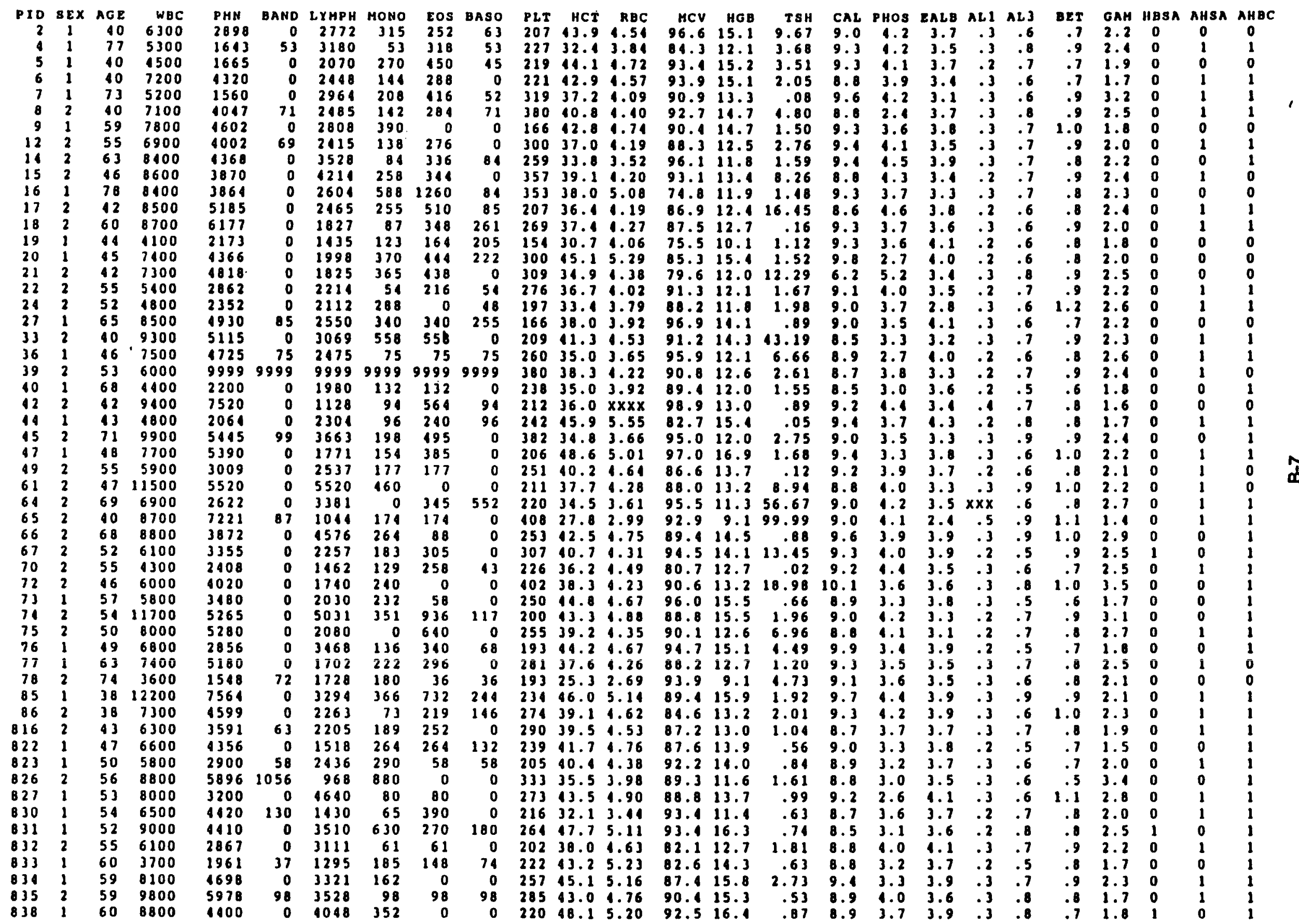




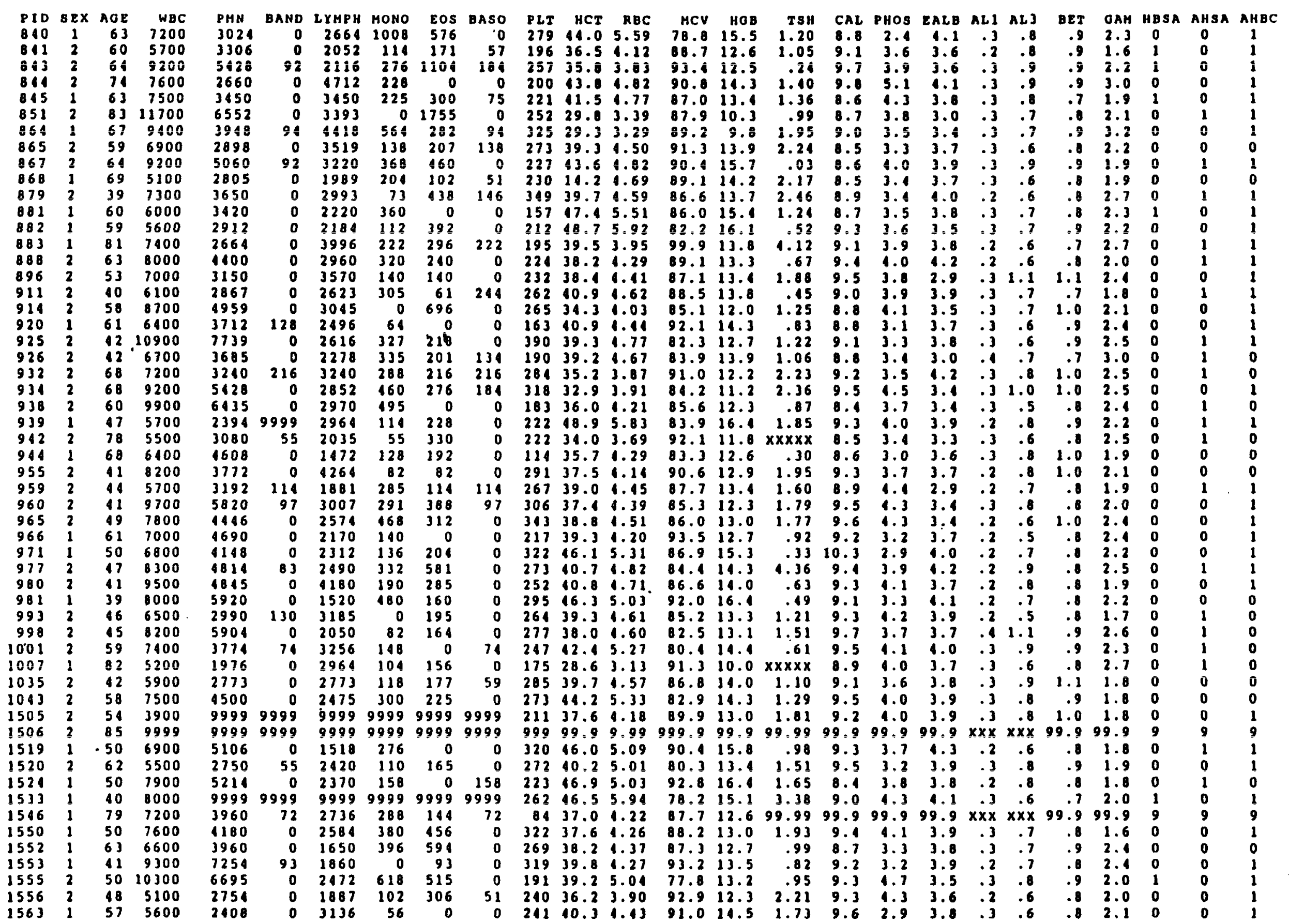


COMPUTER IISTINO OP 1993 RAW DATA

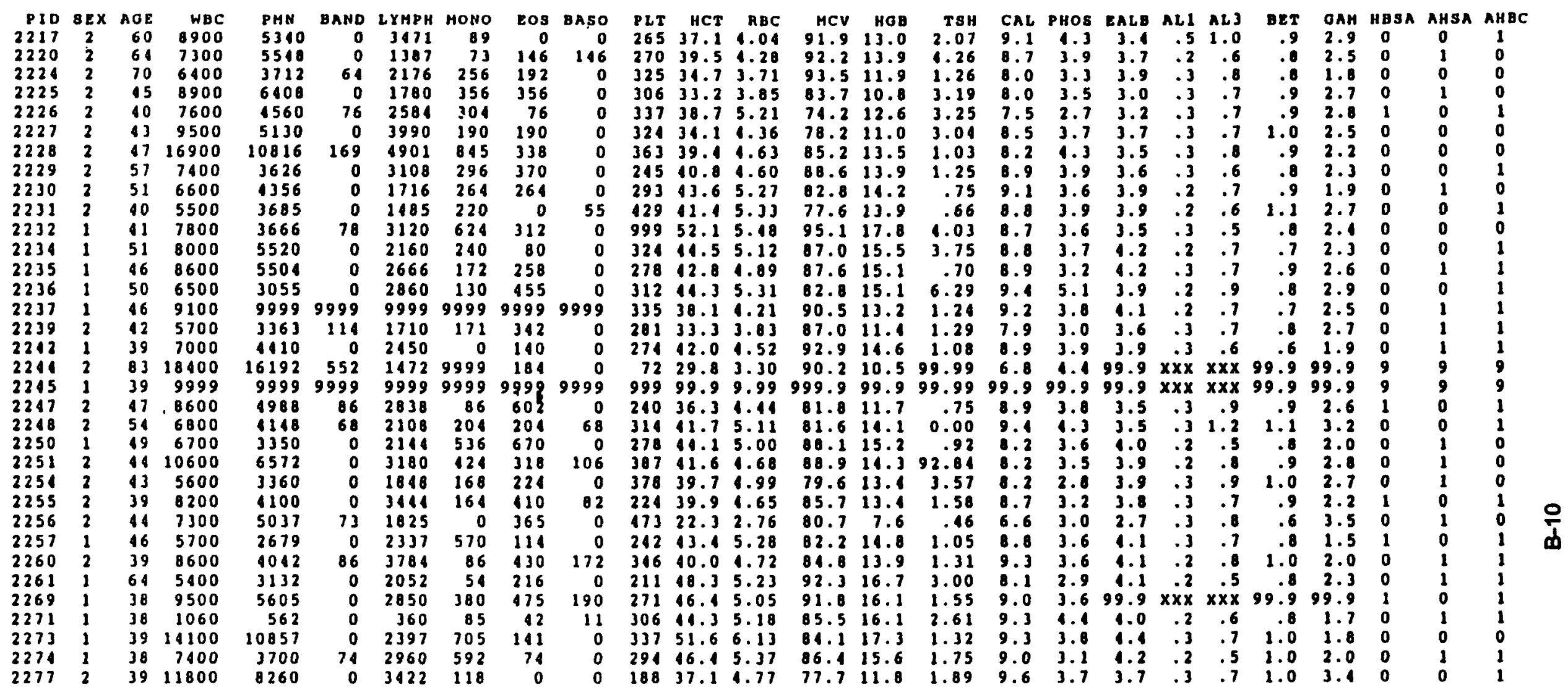


COMPUTER LISTINO OF 1994 RAW DATA

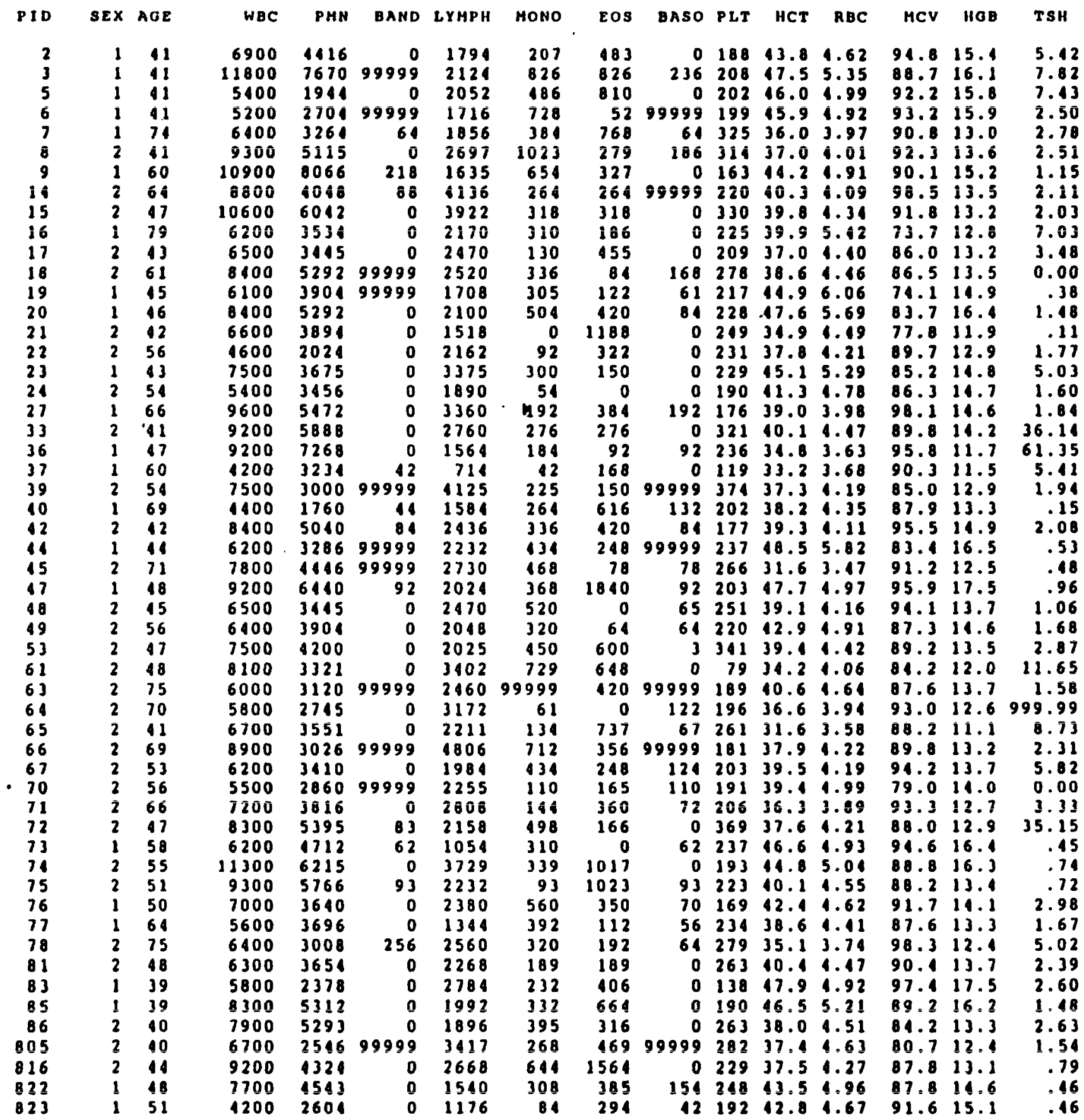


COMPUTER listina OF 1994 RAW DATA

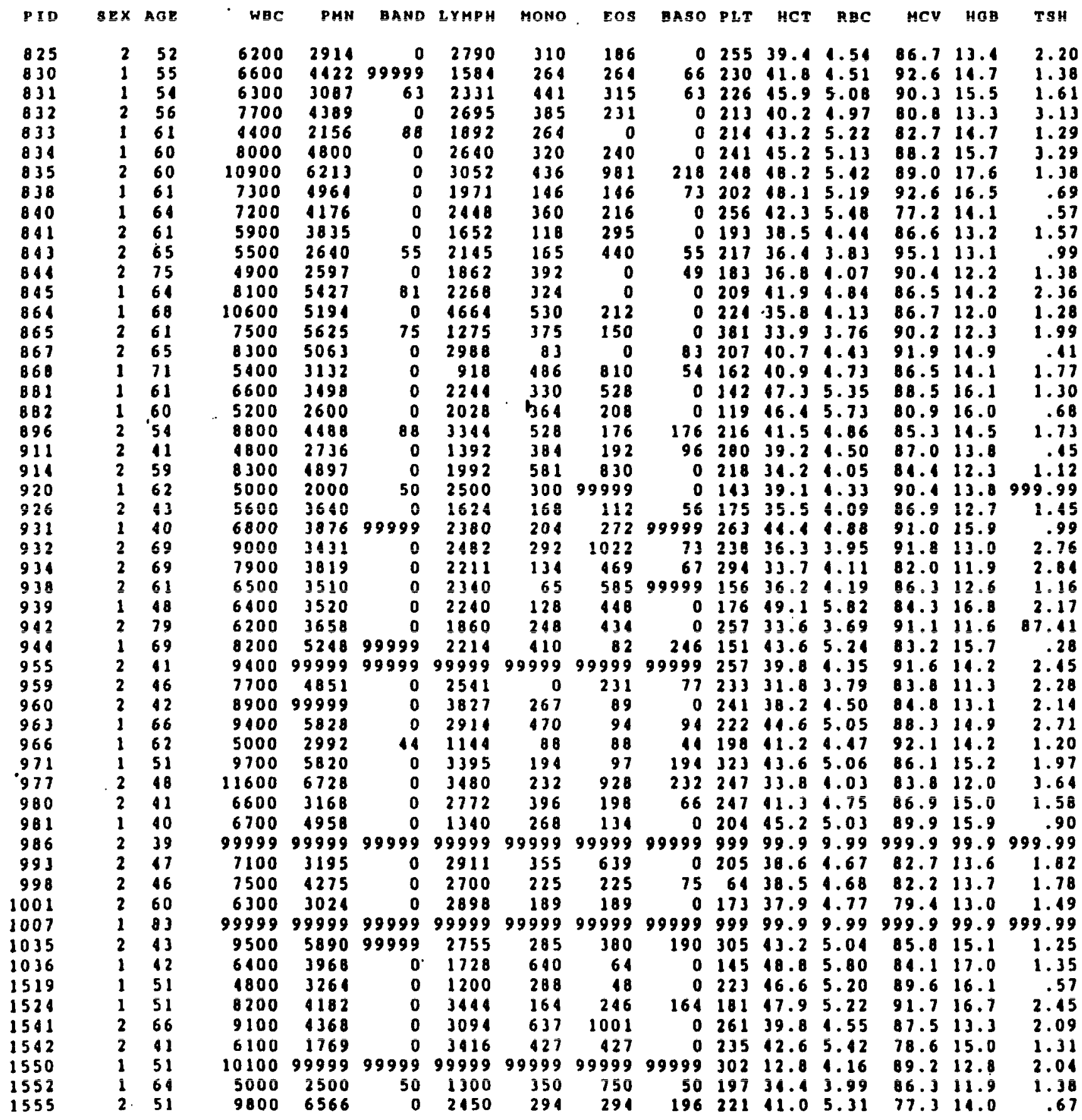


COMPUTER LIETINO OP 1994 RAM DATA

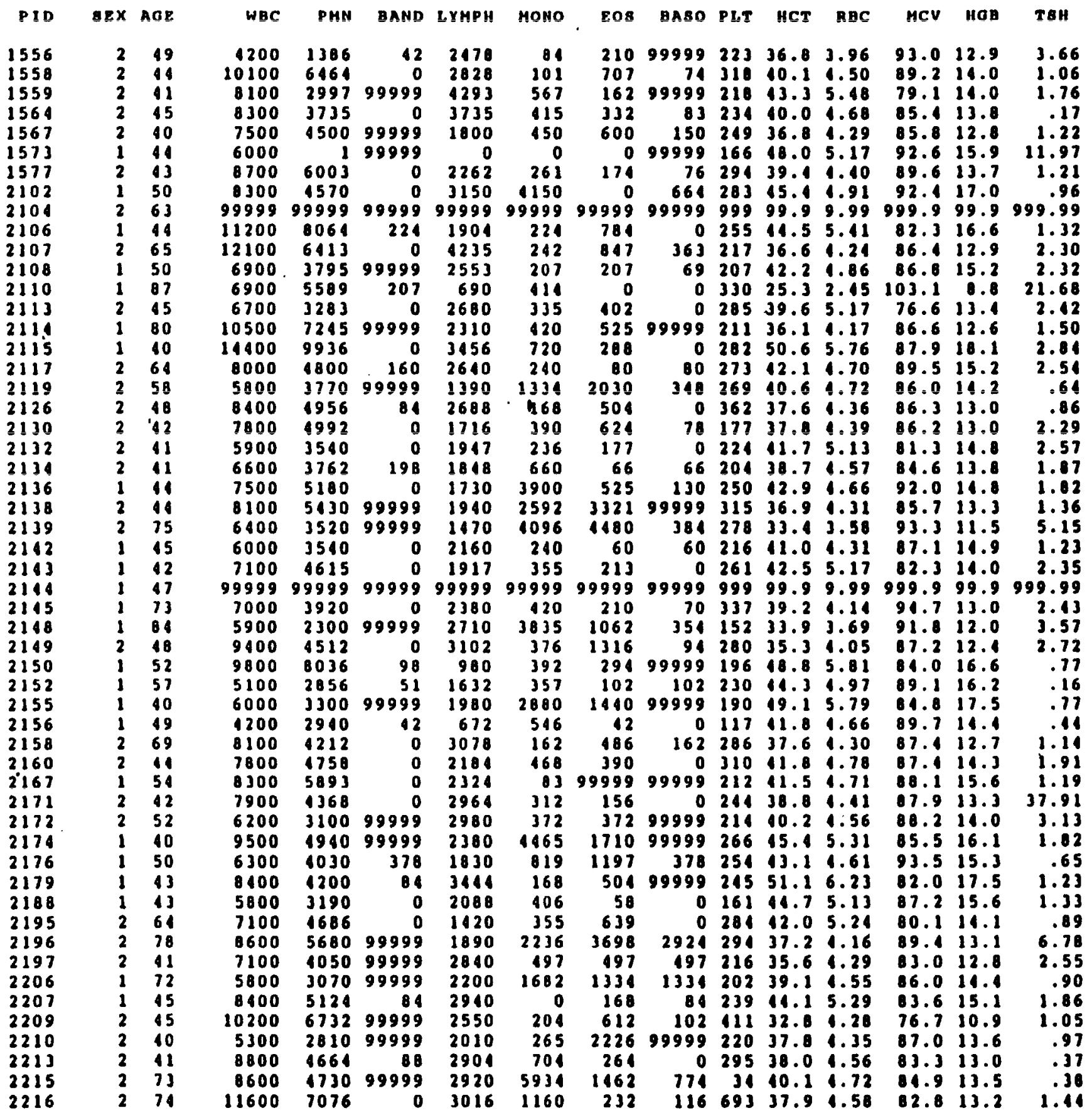


COMPUTER LIating OP 1994 RAW DATA

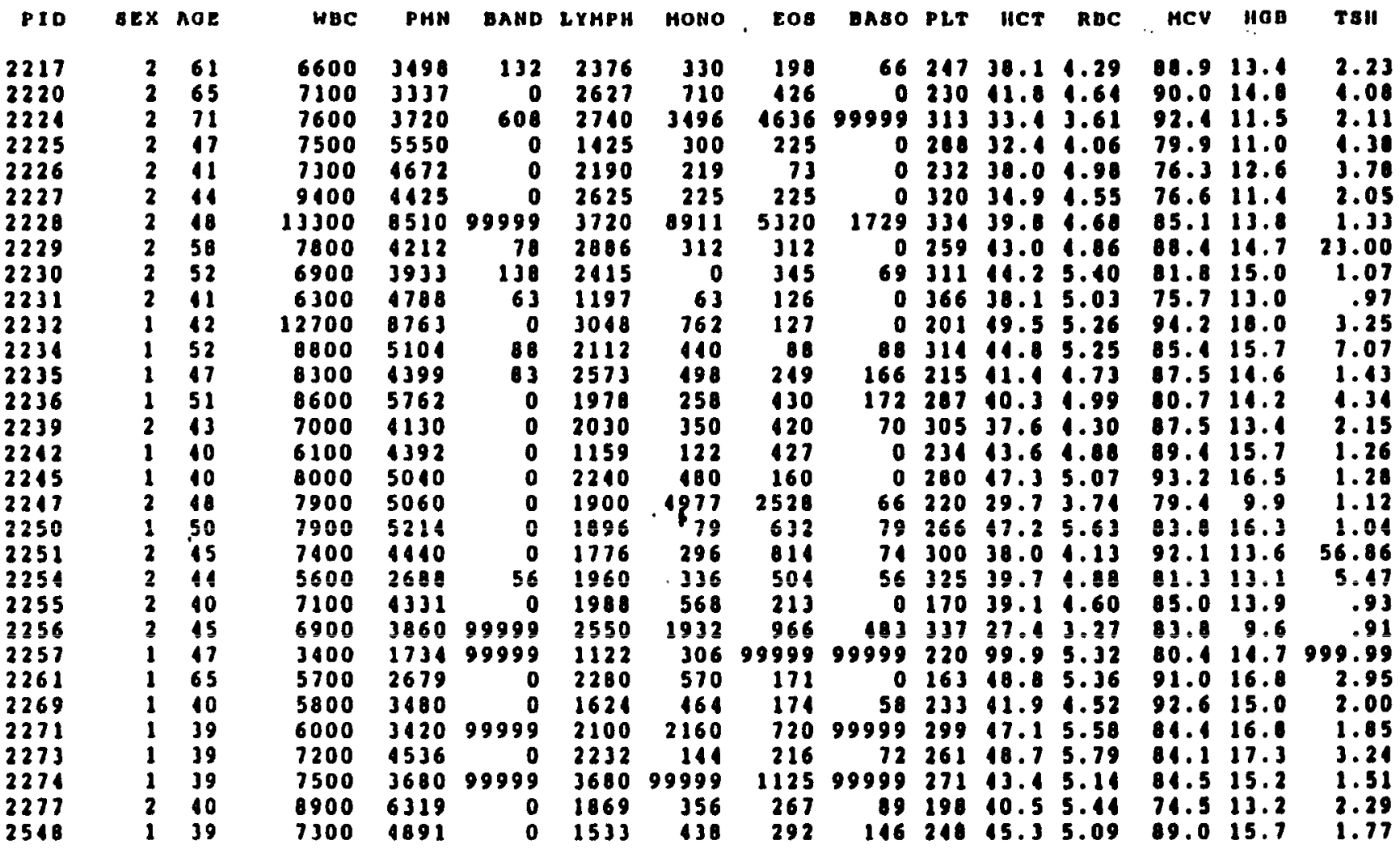




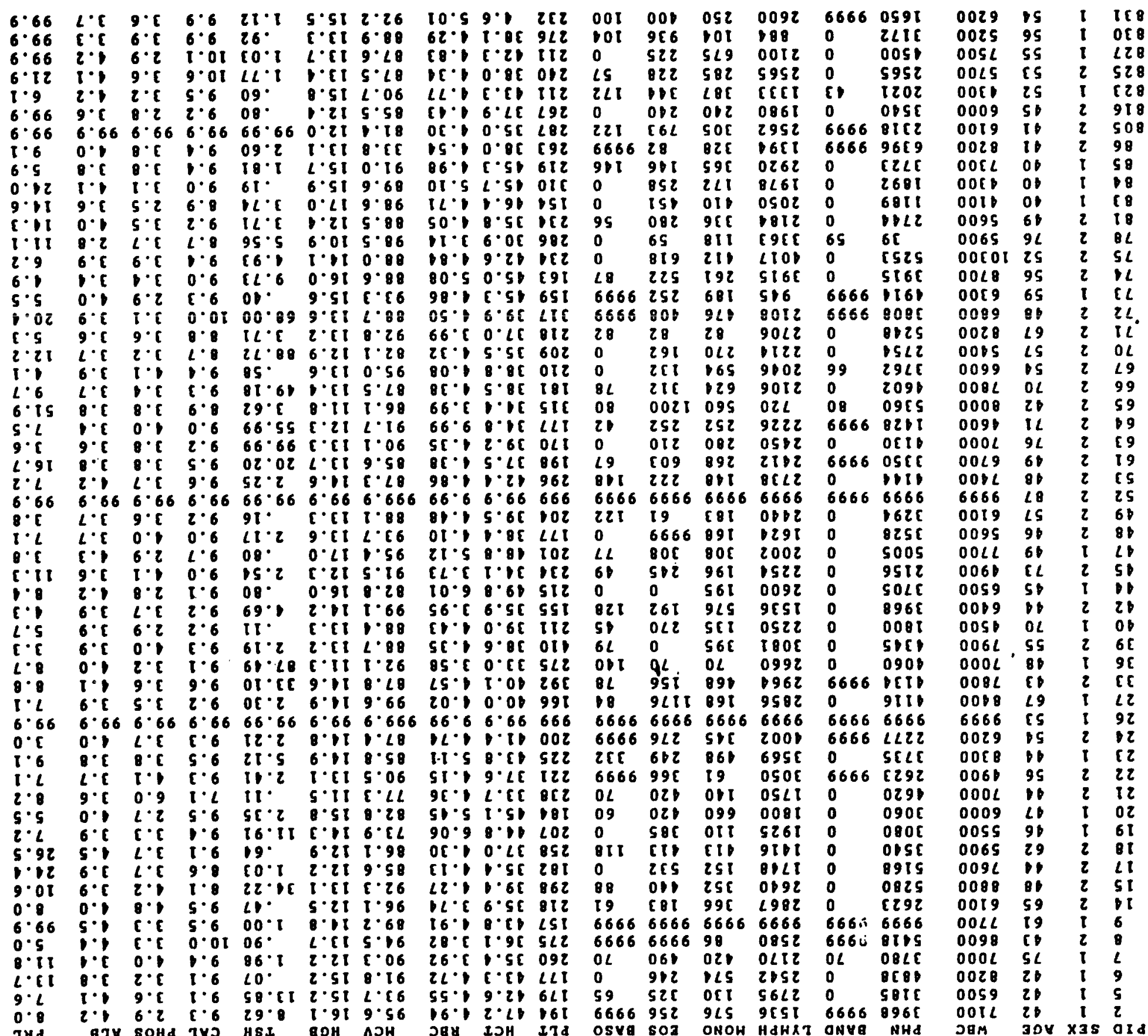




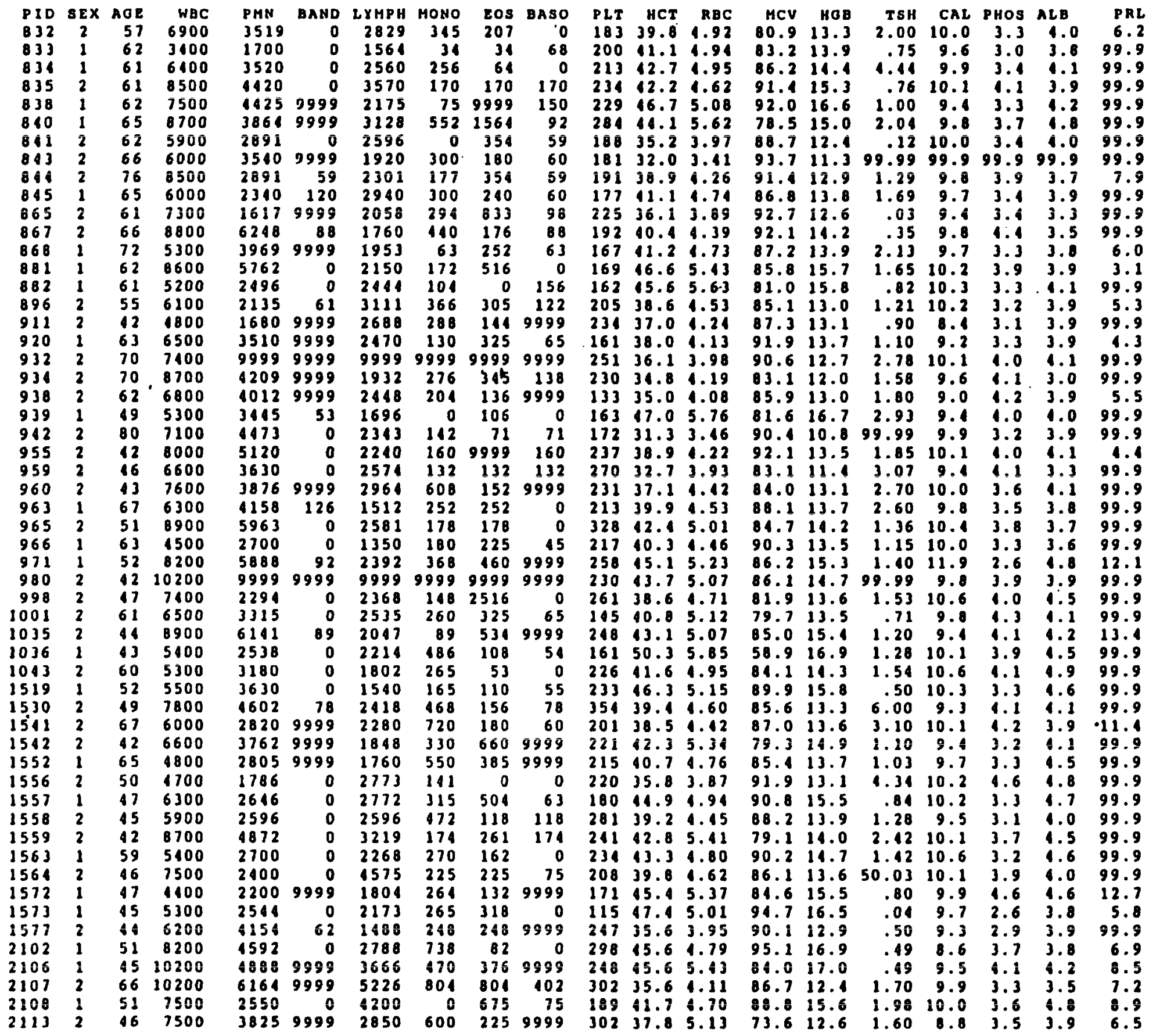


COMPUTER LISTINO OF 1995 RAW DATA

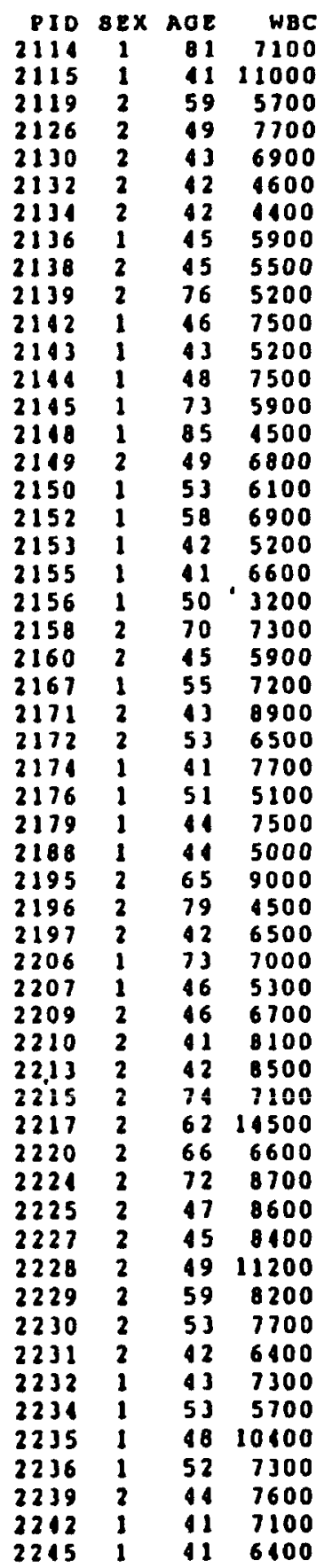

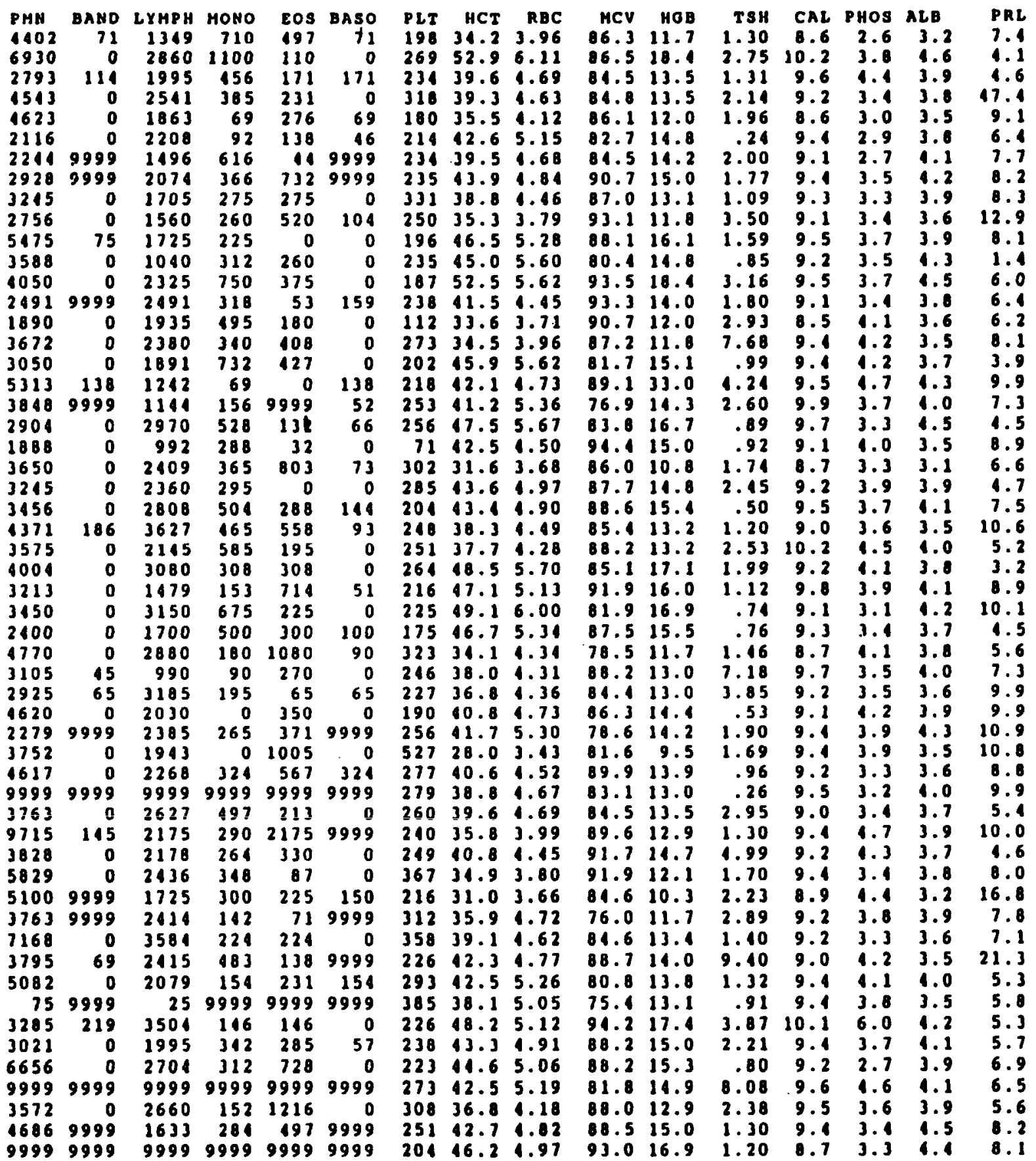


COMPUTER LISTINO OP 1995 RAW DATA

\begin{tabular}{|c|c|c|c|c|c|c|c|c|c|c|c|c|c|c|c|c|c|c|c|}
\hline $\begin{array}{r}P 10 \\
2247 \\
2246 \\
2250 \\
2251 \\
2254\end{array}$ & $\begin{array}{l}8 \mathrm{EX} \\
2 \\
2 \\
1 \\
2 \\
2 \\
2 \\
2 \\
1 \\
2 \\
1 \\
1 \\
1 \\
1 \\
1 \\
1 \\
2 \\
1\end{array}$ & $\begin{array}{l}102 \\
49 \\
56 \\
51 \\
16 \\
16 \\
41 \\
46 \\
48 \\
41 \\
66 \\
41 \\
40 \\
10 \\
41 \\
40 \\
11 \\
40\end{array}$ & $\begin{array}{r}W 8 C \\
6200 \\
7700 \\
9999 \\
11800 \\
4900 \\
8600 \\
5900 \\
9999 \\
9100 \\
6500 \\
7200 \\
6200 \\
5100 \\
8800 \\
7100 \\
14300 \\
6800\end{array}$ & $\begin{array}{l}P H N \\
2600 \\
1389 \\
9999 \\
9676 \\
3038 \\
5676 \\
2891 \\
9999 \\
5460 \\
5005 \\
4104 \\
7622 \\
2754 \\
1488 \\
2698 \\
10582 \\
5016\end{array}$ & $\begin{array}{r}\text { BAND } \\
9999 \\
77 \\
9999 \\
0 \\
9999 \\
86 \\
177 \\
9999 \\
0 \\
130 \\
9999 \\
103 \\
0 \\
88 \\
0 \\
113 \\
0\end{array}$ & $\begin{array}{r}2 Y H P H \\
2860 \\
2079 \\
9999 \\
1770 \\
1568 \\
2064 \\
2360 \\
9999 \\
3094 \\
1105 \\
2664 \\
1957 \\
1734 \\
3168 \\
3337 \\
2574 \\
2904\end{array}$ & $\begin{array}{r}\text { HONO } \\
325 \\
693 \\
9999 \\
354 \\
19 \\
172 \\
118 \\
9999 \\
455 \\
130 \\
360 \\
112 \\
255 \\
528 \\
639 \\
715 \\
616\end{array}$ & $\begin{array}{r}203 \\
715 \\
308 \\
9999 \\
0 \\
245 \\
130 \\
177 \\
9999 \\
0 \\
130 \\
72 \\
206 \\
255 \\
140 \\
142 \\
143 \\
0\end{array}$ & $\begin{array}{r}\text { EAsO } \\
9999 \\
151 \\
9999 \\
0 \\
9999 \\
172 \\
177 \\
9999 \\
91 \\
0 \\
9999 \\
9999 \\
51 \\
88 \\
213 \\
113 \\
264\end{array}$ & $\begin{array}{l}P L T \\
205 \\
327 \\
999 \\
343 \\
306 \\
185 \\
291 \\
999 \\
346 \\
176 \\
190 \\
244 \\
283 \\
279 \\
278 \\
253\end{array}$ & $\begin{array}{r}H C T \\
37.9 \\
10.0 \\
99.9 \\
11.9 \\
36.6 \\
38.8 \\
28.1 \\
99.9 \\
12.2 \\
48.0 \\
51.0 \\
14.8 \\
13.1 \\
18.5\end{array}$ & $\begin{array}{l}R B C \\
1.58 \\
1.82 \\
9.99 \\
1.69 \\
1.56 \\
1.55 \\
3.39 \\
9.99 \\
1.91 \\
5.22 \\
6.16 \\
1.91 \\
5.16 \\
5.79 \\
5.29 \\
5.12 \\
5.07\end{array}$ & $\begin{array}{r}M C V \\
02.7 \\
82.9 \\
999.9 \\
88.1 \\
80.3 \\
85.2 \\
82.8 \\
999.9 \\
85.1 \\
91.9 \\
82.8 \\
91.2 \\
83.5 \\
83.8 \\
81.3 \\
71.6 \\
92.2\end{array}$ & $\begin{array}{r}108 \\
13.0 \\
14.0 \\
99.9 \\
14.3 \\
13.0 \\
11.3 \\
9.7 \\
99.9 \\
11.9 \\
16.6 \\
17.4 \\
15.6 \\
15.7\end{array}$ & $\begin{array}{r}784 \\
.92 \\
23.15 \\
1.10 \\
9.11 \\
1.20 \\
.71 \\
.88 \\
1.00 \\
.05 \\
3.10 \\
1.50 \\
1.63 \\
1.94 \\
1.84 \\
1.05 \\
3.54 \\
1.88\end{array}$ & $\begin{array}{r}\text { CA. } \\
9.9 \\
10.2 \\
9.3 \\
9.6 \\
9.1 \\
9.1 \\
9.2 \\
9.1 \\
10.2 \\
9.1 \\
10.2 \\
9.6 \\
9.8 \\
10.8 \\
9.7 \\
9.1 \\
9.3\end{array}$ & $\begin{array}{l}1.4 \\
3.1 \\
3.6 \\
3.2 \\
1.3 \\
2.7 \\
3.8 \\
1.0 \\
3.9 \\
3.1 \\
4.8\end{array}$ & $\begin{array}{c}A L B \\
3.8 \\
1.1 \\
1.1 \\
1.1 \\
1.0\end{array}$ & $\begin{array}{r}P R 2 \\
5.1 \\
1.0 \\
10.5 \\
19.5 \\
13.1 \\
12.1 \\
3.7 \\
13.1 \\
39.2 \\
7.1 \\
3.1 \\
1.2 \\
8.1 \\
13.1 \\
2.1\end{array}$ \\
\hline
\end{tabular}




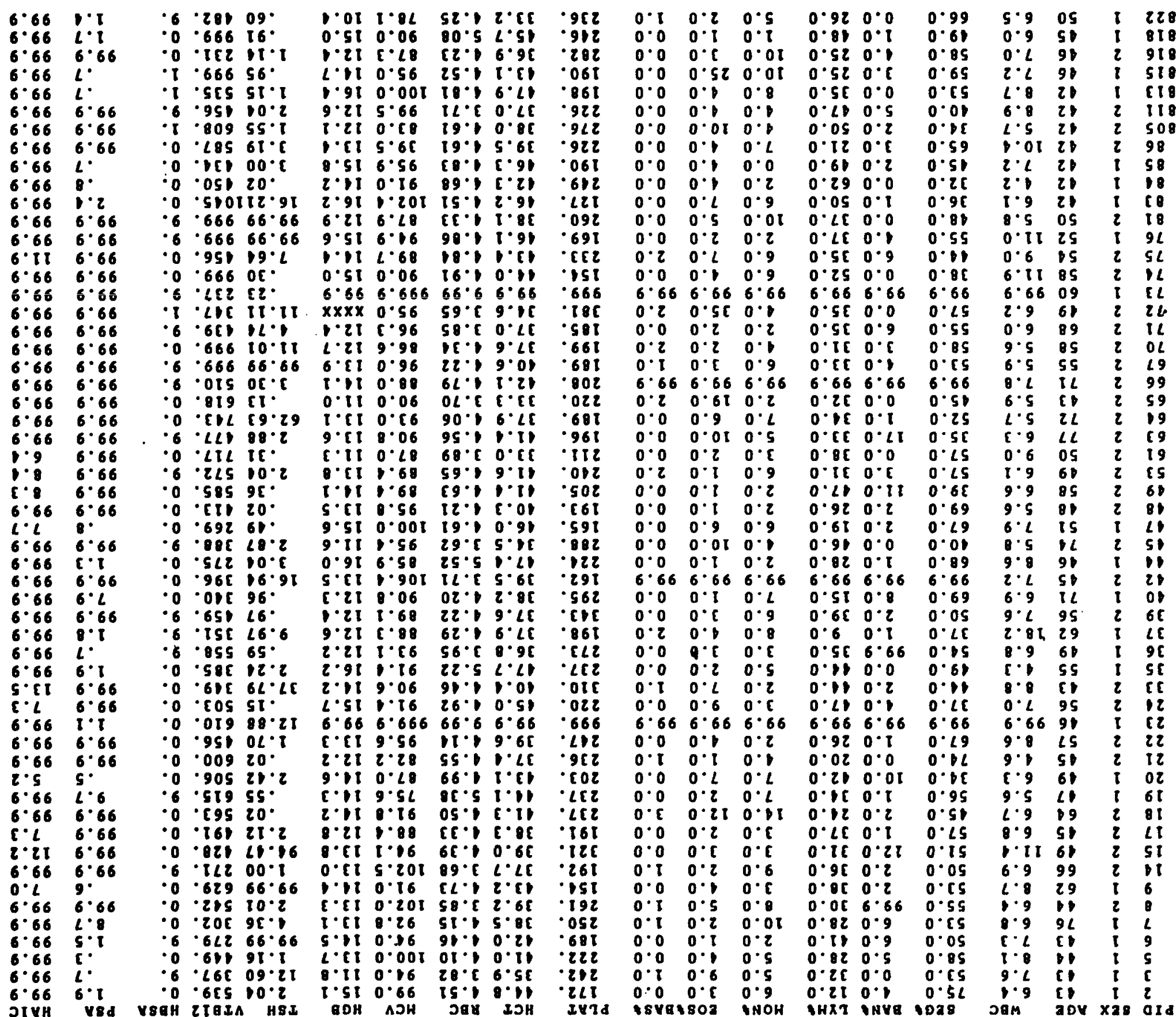




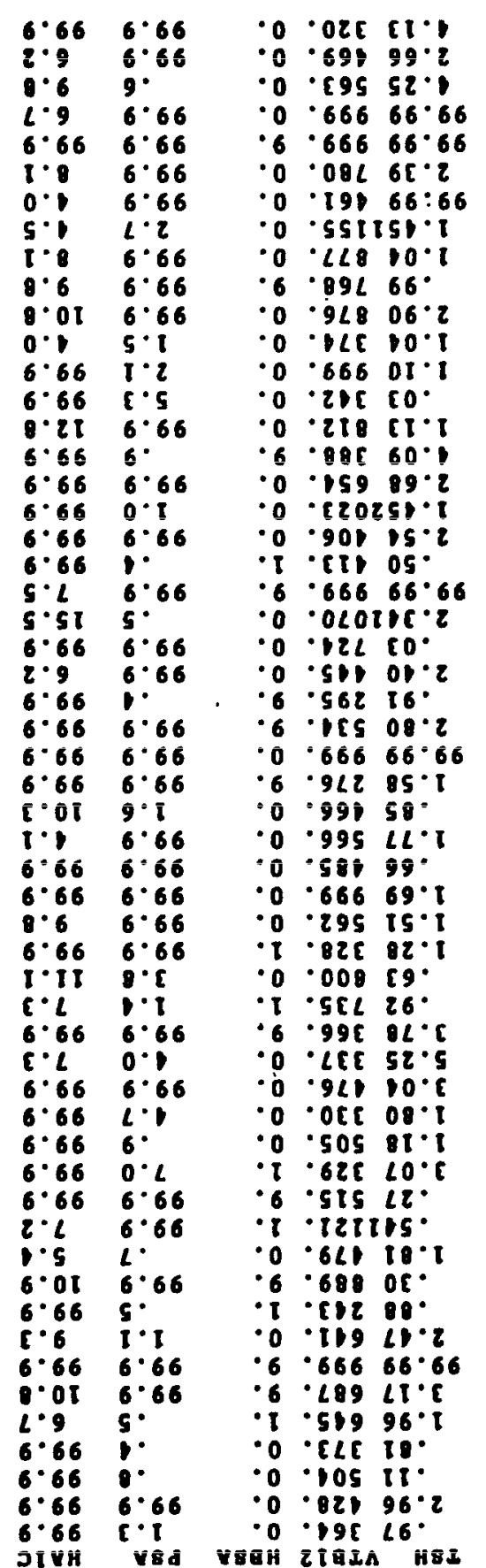

$\begin{array}{llllll}2.21 & 0.06 \quad 21 \cdot 16.96 & 065\end{array}$

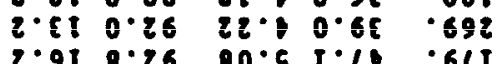
$2.919 .26 \quad 80.551 .28 \quad .621$ $\begin{array}{llllll}0.91 & 0.16 & 51.5 & 6.91 & \cdot 102\end{array}$ $6.66 \quad 6.666 \quad 66.6 \quad 6.66 \quad 666$ L.2T $0.16 \quad 10.16 .95 \quad .691$ $\begin{array}{lllll}9 \cdot 11 & 1 \cdot 58 & 82 \cdot 1 & 9 \cdot 52 & .012 \\ 1.91 & 0.88 & 85.5 & 8.96 & .202\end{array}$ $\begin{array}{rrrrr}-991 & 0.98 & 85.5 & 8.96 & 202 \\ 2.11 & 0.68 & 10.1 & 8.28 & .252\end{array}$

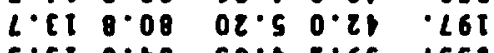
$5.110 .68 \quad 59.18 .68 \quad .552$ $2.510 .56 \quad 21.22 .55 \quad .602$

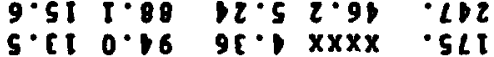

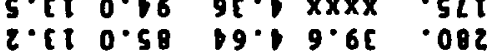
- 111.06 is.16.01 . 661

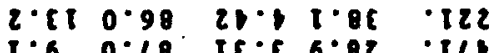
$1.6 \quad 0.28$ tद.6 $6 \cdot 8 z \quad 1 \angle 1$

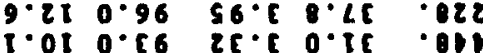
c. It $5.06 \quad \angle 9 \cdot E \tau \cdot c$ C $\angle 0 Z$

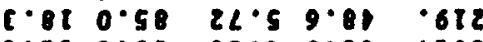
t.21 0.88 01. 6.5e 102

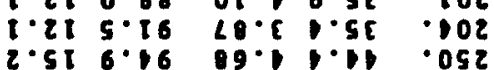

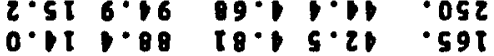

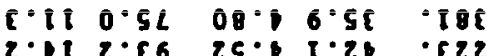

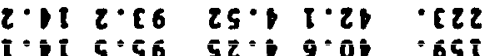
- II 0.68 06.6 8.16 -212 i.ti o. $8.510 .56 \quad 18.9 .68$

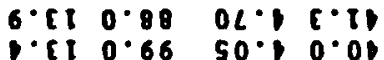
$\begin{array}{llll}0.11 & 0.66 & 50.1 & 0.08 \\ 6.11 & 0.28 & 25.5 & 6.88\end{array}$ 0.915 .88 LE.5 $5 \cdot 20$. 181

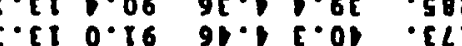
$0.810 .56 \quad 1005.86 \quad 512$ $9.910 .56 \quad 60.5 \mathrm{t} .80$.512 5.61 $1 \cdot 16 \quad 25.12 \cdot 11 \cdot 261$

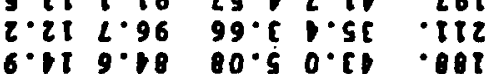
6.119 .18 80.5 $0.54 \quad .089$ $6.110 .08 \quad \angle 9.5 \quad 5.51 \quad$. 828 द. 11.16 12.? 9.86 ? s.51 0.06 10.5 0.58 -052 s.ह1 g.58 $2 L \cdot \%$ 6.01 . 202 -21 $2.2869 .19 \cdot 06$ -51 .E6 $25 \cdot 0.51$ $\begin{array}{llll}0.11 & 0.96 & 92 .: & 6.08 \\ .21 & 0.86 & 51 . & 5.86\end{array}$

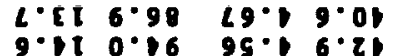
$\begin{array}{lllll}0.0 & 0.6 & 0.5 & 0.56 & 0.0\end{array}$ $\begin{array}{llll}0.0 & 0.2 & 0.2 & 0.210 .0\end{array}$ $0.1 \quad 0.2 \quad 0.100 .210$. $0.0 \quad 0.8 \quad 0.6 \quad 0.42 \quad 0.5$ $6.660 .666 .66 \quad 6.660 .660 .296$ $\begin{array}{llllll}0.0 & 0.6 & 0.6 & 0.92 & 0.5\end{array}$ $0.0 \quad 0.0 \quad 0 . \varepsilon \quad 0.15 \quad 0.2$ $0.0 \quad 0.1 \quad 0.2$ $0.1 \quad 0.6 \quad 0.5$ $0.0 \quad 0.5 \quad 0.6$ $0.0 \quad 0.1 \quad 0.9$ $\begin{array}{llll}0.1 & 0.2 & 0.1\end{array}$ $0.0 \quad 0.0 \quad 0.1$ $0.1 \quad 0.0 \quad 0.6$ $0.1 \quad 0.5 \quad 0.1$ $\begin{array}{lll}0.0 & 0.2 & 0.6 \\ 0.1 & 0.1 & 0.1\end{array}$ $\begin{array}{lll}0.0 & 0.2 & 0.2 \\ 0.0 & 0.5 & 0.2\end{array}$ 0.00 .00 .8 $0.0 \quad 0.0 \quad 0.9$ $0.0 \quad 0.5 \quad 0.5$ $0.0 \quad 0.1 \quad 0.1$ $\begin{array}{llll}0.0 & 0.0 & 0.2\end{array}$ $0.0 \quad 0.015 .6$ $\begin{array}{lll}0.0 & 0.5 & 0.2 \\ 0 \cdot 0 & 0.1 & 0 \cdot c\end{array}$ $\begin{array}{ccc}0.0 & 0.6 & 0.2\end{array}$ $\begin{array}{lll}0.1 & 0.2 & 0.2\end{array}$ $\begin{array}{lll}0=i & 0.01 & 0.5\end{array}$ $0.0 \quad 0 * i \quad 0=i$ $0.0 \quad 0.9 \quad 0.2$ $\begin{array}{lll}0.0 & 0.2 & 0.1\end{array}$ $\begin{array}{lll}0.0 & 0.5 & 0.2 \\ 0.0 & 0.6 & 0.1\end{array}$ $\begin{array}{lll}0.0 & 0.2 & 0.5 \\ 0.0 & 0.0 & 0.0\end{array}$ $0.1 \quad 0.010 .2$ $0.0 \quad 0.250 .1$ 0.00 .00 .1 $0.0 \quad 0.0 \quad 0.2$ $0.1 \quad 0.6 \quad 0.5$ $\begin{array}{lll}6.66 & 6.66 & 6.66 \\ 0.0 & 0.21 & 0.6\end{array}$ 6.66 6.66 6.66 0. it 0.2 $\begin{array}{ll}0.68 & 0.8 \\ 0.12 & 0.0\end{array}$ 0. औद 0.2 0.910 .8 $0 . \angle 2 \quad 0.0$ 0. is 0.9 . Se 0.0 o. OE 0.5 0.22 o.: $0.0,0.1$ 0.8 \& 0.2 0.910 .5 a. . Os 0.0 $0.0 \mathrm{r}$ 0.060 .5 0.910 .0 . 910.1 0.020 .0 0.0 .0250 .0 0.0820 .0 $0.050 .0 \quad 0.02$ 0.850 .0 $0.62 \quad 0.0$ 0.89 . 0.6 0.920 .9 $\begin{array}{lll}0.26 & 0.2\end{array}$ 0.012 0.250 .0 0.080 .1 0. LE 0.0

0.55 080.90 .68 .520 .110 .61 $\begin{array}{lll}0.620 .6 & 0.05\end{array}$ $\begin{array}{lllll}0.0 & 0.6 & 0.28 & 0.8 & 0.28\end{array}$ $\begin{array}{llllll}0.0 & 0.0 & 0.55 & 0.52 & 0.2 & 0.85\end{array}$ $0.1 \quad 0.0 \quad 0.6$ 0.82 .061 o.t $0.1 \quad 0.2$ 0.000 .10 .5 $0.0 \quad 0.11 \quad 0.8$ $\begin{array}{lll}0.0 & 0.8 & 0.01 \\ 0.1 & 0.9 & 0.2\end{array}$ $\begin{array}{llllllll}0.11 & 0.16 & 95.16 .20 & 601 & 0.0 & 0.2 & 0.01\end{array}$ $0.5 E$. 0.8 O.B. 0. E 0.6 O. $0.110 .1 \quad 0.69$ $\begin{array}{lll}0.25 & 0.2 & 0.25 \\ 0.25 & 0.12 & 0.10\end{array}$ 0.910 .1

6) $L \cdot L \quad 89 \quad 2$ IVSI il $2 \cdot 2$ Cs 2 ses

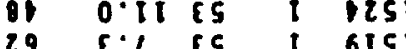
$6.6666666 \quad 6605$ LS 2 SOS

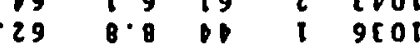
$\begin{array}{lllll}25 & 8.5 & 5 & 2 & 560 \\ 0.2 & 9.2 & 29 & 2 & 1001\end{array}$ $91 \quad 1260 \quad 2 \quad 866$ $\begin{array}{lllll}19 & 6 & 26 & 1 & 186\end{array}$ $\begin{array}{llll}19 & 1.5 & 89 & 1\end{array}$ $\begin{array}{lllll}65 & 2 & 25 & 2 & 596\end{array}$ $\begin{array}{lllll}25 & 2.5 & 89 & 1 & 596\end{array}$ 5.6
2.6 $\begin{array}{llll}2.6 & 16 & 2 & 556\end{array}$ 0.5 is 2 $5 \cdot 8$ O5 1616 $9.5 \quad 192016$ $1 \cdot 2$ IL 2 256

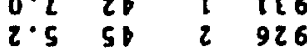
8 51 2526 $\begin{array}{llll}1.5 & I 2 & 226\end{array}$ .2192502 $2=5$ हो $\bar{t}$ i 16 $2.6 \quad 982606$ $1.695 \quad 2 \quad 968$ $\begin{array}{llll}1.2 & 8 & 2 & 168 \\ 6.8 & 59 & 1 & 288\end{array}$ 6.8191188 $6.2 \quad 212628$

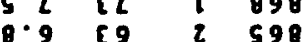
$\begin{array}{lllll}\circ & O L & 1 & 190\end{array}$ - $0898 \quad 1 \quad 98$ . 992568 68192688

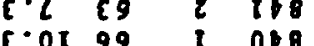
$6.98926 C$ $0.6 \quad 592068$ $\begin{array}{lll}0.6 & 29 & 1\end{array}$ - E la I EE $8.5 \quad 852258$ 6.5 85 I OE $6.295 \quad 1 \quad 128$ 0.9 bs 2528 9.5 ES I 520 


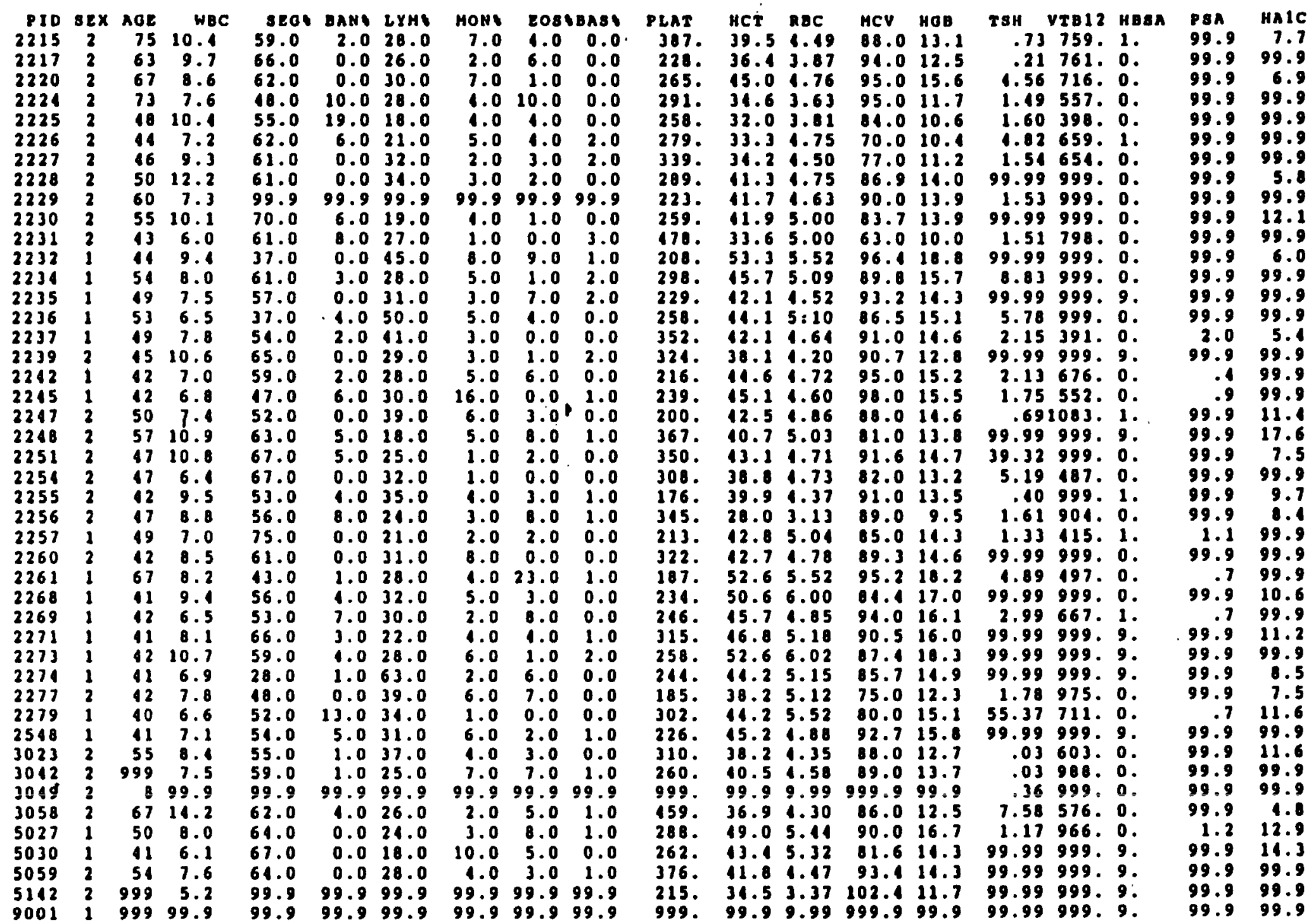

